OPEN ACCESS

Edited by:

Christoph Franz Kurat, Ludwig Maximilian University

of Munich, Germany

Reviewed by:

Thomas M. Vondriska, University of California, Los Angeles,

United States

Tuncay Baubec,

University of Zurich, Switzerland

${ }^{*}$ Correspondence: Amelie Fradet-Turcotte amelie.fradet-turcotte@ crchudequebec.ulaval.ca Jacques Côté jacques.cote@ crchudequebec.ulaval.ca

tThese authors have contributed equally to this work and share first authorship

FThese authors have contributed equally to this work and share last authorship

Specialty section:

This article was submitted to

Epigenomics and Epigenetics, a section of the journal Frontiers in Cell and Developmental

Biology

Received: 23 June 2021 Accepted: 24 August 2021 Published: 16 September 2021

Citation:

Galloy M, Lachance C, Cheng X

Distéfano-Gagné F, Côté $J$ and Fradet-Turcotte A (2021) Approaches to Study Native Chromatin-Modifying

Complex Activities and Functions.

Front. Cell Dev. Biol. 9:729338.

doi: 10.3389/fcell.2021.729338

\section{Approaches to Study Native Chromatin-Modifying Complex Activities and Functions}

\author{
Maxime Galloy ${ }^{1,2+}$, Catherine Lachance ${ }^{1,2+}$, Xue Cheng ${ }^{1,2}$, Félix Distéfano-Gagné ${ }^{1,2}$, \\ Jacques Côté ${ }^{1,2 * \neq}$ and Amelie Fradet-Turcotte ${ }^{1,2 * \neq}$ \\ ${ }^{1}$ St-Patrick Research Group in Basic Oncology, Oncology Division, Centre Hospitalier Universitaire (CHU) \\ de Québec-Université Laval Research Center, Québec, QC, Canada, ${ }^{2}$ Department of Molecular Biology, Medical \\ Biochemistry and Pathology, Laval University Cancer Research Center, Université Laval, Québec, QC, Canada
}

The modification of histones - the structural components of chromatin-is a central topic in research efforts to understand the mechanisms regulating genome expression and stability. These modifications frequently occur through associations with multisubunit complexes, which contain active enzymes and additional components that orient their specificity and read the histone modifications that comprise epigenetic signatures. To understand the functions of these modifications it is critical to study the enzymes and substrates involved in their native contexts. Here, we describe experimental approaches to purify native chromatin modifiers complexes from mammalian cells and to produce recombinant nucleosomes that are used as substrates to determine the activity of the complex. In addition, we present a novel approach, similar to the yeast anchor-away system, to study the functions of essential chromatin modifiers by quickly inducing their depletion from the nucleus. The stepby-step protocols included will help standardize these approaches in the research community, enabling convincing conclusions about the specificities and functions of these crucial regulators of the eukaryotic genome.

\footnotetext{
Keywords: chromatin, histone modification, native protein complexes, recombinant nucleosomes, nuclear protein depletion
}

\section{INTRODUCTION}

Understanding chromatin structure and function has been a focus of intense research for decades. It is now well established that the chromatin plays primary active roles regulating genome-related processes, including gene-specific expression, DNA damage repair, and DNA replication during cell division (Allis and Jenuwein, 2016). Every few years, breakthrough discoveries propel the field into new territories, expanding our understanding of the molecular mechanisms involved and providing crucial insights on human diseases like cancer, an illness with combined genetic and epigenetic origins (Shen and Laird, 2013). This has led to an impressive surge in the development of epigenetic approaches to treat cancer (Brien et al., 2016). The research breakthroughs that have allowed these leaps have been conceptual, such as the identification of histone writers/readers/erasers, as well as technological, including approaches to study genome organization and modifications with increasing precision. 
The epigenetic language written on the chromatin has been studied for over 20 years, and new mechanistic understandings continuously emerge. The post-translational modifications (PTMs) of conserved histone residues are diverse, and their combinations form specific signatures that can be read by effectors. As the same PTM can have opposing functions when added on different residues/histones, it is crucial to clearly identify and characterize the chromatin modifiers regulating each specific modified histone residue, as well as the reader proteins that recognize them. Historically, many studies have used histone peptides or free histones to identify the enzymes responsible for specific PTMs, as well as recombinant proteins instead of enzymes in their native forms. However, the specificities identified in these studies are often significantly different from those observed in vivo or when assayed in vitro on chromatin substrates (reviewed in Lalonde et al., 2014). In fact, true native specificity can only be reproduced in a test tube using native substrates, nucleosomal histones/chromatin, and enzymes in their physiological contexts, including any associated factors. It is clearly established that the histone residue specificity of chromatin modifiers can be determined by associated factors within large enzyme-containing protein complexes (Lalonde et al., 2014). In addition, associated reader modules within these large complexes further regulate the specificity of the modifiers by mediating crosstalk between different histone modifications (Lalonde et al., 2014).

In parallel, determining chromatin modifier specificity in vivo can be difficult because of their possible indirect effects on the modifications of other specific residues. Indeed, many histone PTMs are regulated by crosstalk between histone modifications, a phenomenon that can induce secondary effects when histone modifiers are depleted or knocked out (McGinty et al., 2008; Lalonde et al., 2014; Jacquet et al., 2016; Wojcik et al., 2018; Zhang and Kutateladze, 2019). This is a major reason why both in vivo and in vitro experiments are required to truly understand the intricate molecular mechanisms regulating chromatin modifiers.

\section{APPROACHES TO CHARACTERIZE CHROMATIN-MODIFYING ENZYME ACTIVITIES AND FUNCTIONS}

Over the years, multiple approaches to purify native protein complexes from mammalian nuclear extracts (NEs) have been developed. Several chromatin remodeling and modifying complexes have been efficiently purified to near homogeneity by introducing transgenes encoding tagged components. Tandem affinity purification (TAP) was developed more than 20 years ago in yeast and quickly transferred to higher eukaryotes (Rigaut et al., 1999; Puig et al., 2001). Different tag combinations have been tested, some of which provide high specificity and efficient elutions/high yields in native conditions. For example, the FLAG epitope has remained front and center for many years (Hopp et al., 1988; Einhauer and Jungbauer, 2001). However, one of the main issues with this approach is the formation of artefactual associations due to overexpression of the transgene compared to the physiological protein level (Gibson et al., 2013;
Lalonde et al., 2014). This often occurs when proteins with significant homology (paralogs) to specific subunits or even the tagged protein are expressed. Keeping expression at a nearphysiological level is possible, by aiming for single-copy genome integration and using different promoter strengths [e.g., using retroviral vectors at low multiplicity of infection or the Flp- $\mathrm{In}^{\mathrm{TM}}$ system (Thermo Fisher Scientific)]. Random genome integration can also create problems due to well-established positional effects on gene expression depending on the local chromatin state. Thus, achieving near-physiological expression can require isolating and characterizing multiple clones. The development of safe harbors for transgene integration has great advantages because the different cell lines created are isogenic, as in lower eukaryotes. The AAVS1 and ROSA26 loci have been frequently used for this purpose, and recent genome editing tools have made this endeavor quite straightforward (DeKelver et al., 2010; Sadelain et al., 2012; Dalvai et al., 2015). Of course, the gold standard of reproducing physiological conditions is to tag the endogenous gene and use it to purify the native chromatin modifying complex. This can now also be achieved, thanks to the power of clustered regularly interspaced short palindromic repeats (CRISPR)/Cas9-based genome editing (Dalvai et al., 2015).

To obtain native chromatin substrates, several protocols are available to purify endogenous chromatin from human cell lines (Côté et al., 1995; Utley et al., 1996; Schnitzler, 2000). Substrates are produced by micrococcal nuclease digestion and can be fractionated in different lengths, from long oligonucleosomes to mononucleosomes. They have several advantages: they already contain the vast majority of known histone marks, reproduce the natural substrate, and enable binding specificity analysis. However, these marks are present at low stoichiometries on each residue, and the DNA sequences associated with the nucleosomes are heterogeneous. Using recombinant histones to assemble nucleosome core particles (NCPs) is a powerful alternative to producing chromatin substrates with defined DNA and histone status. The "Widom" sequence is extremely efficient for nucleosome assembly/positioning using recombinant histone octamers (Lowary and Widom, 1998; Thåström et al., 1999). The resulting recombinant nucleosomes are homogeneous, and their main advantage is that they can be enzymatically or chemically modified to introduce a specific histone PTM at a given residue with high stoichiometry. This allows very clear analysis of crosstalk occurring between different histone marks, via specific reader proteins, or within chromatin remodeling/modifying complexes. Over the past few years, the use of purified native chromatin modifying complexes and recombinant nucleosomes has produced exquisite highresolution $3 \mathrm{D}$ structures of chromatin-bound complexes, which have provided crucial mechanistic insights (Poepsel et al., 2018; Patel et al., 2019; Farnung et al., 2020; Wagner et al., 2020; Wang et al., 2020).

In vivo loss of function analysis of chromatin modifiers has relied mostly on RNA interference-mediated depletion and mouse gene knockouts. However, these can create indirect and/or downstream effects that mask the primary role of the enzyme being studied (discussed in Lalonde et al., 2014). For example, depletion of chromatin modifiers such as the HBOI 
acetyltransferase, impact cell cycle progression into $S$ phase (Doyon et al., 2006; Miotto and Struhl, 2010; Havasi et al., 2013; Feng et al., 2016). As many chromatin modifiers are essential for cell viability or normal growth and because several histone marks are regulated during the cell cycle (Ma et al., 2015), changes due to of knockdown of such factors can mislead the investigator into linking a chromatin modification to a specific enzyme (Lalonde et al., 2014). The development of rapid depletion approaches, as used in lower eukaryotes, can bypass these problems. The auxininducible degron has proved popular; however, the tag is known to affect protein stability even in the absence of auxin, which can be alleviated by expressing transport inhibitor response 1 (Nishimura et al., 2020; Yesbolatova et al., 2020). The recently described degradation TAG does not seem to have the same problem, and efficiently and suddenly targets proteins to the proteasome (Nabet et al., 2018).

In this method article, we present up-to-date detailed protocols related to the approaches discussed above. First, we describe the use of the $3 \times$ FLAG- $2 \times$ Strep tag fused to a gene of interest (either expressed from AAVS1 or endogenously tagged) to purify native chromatin modifying complexes for biochemical/enzymatic assays. Second, we provide a step-bystep protocol for the production of recombinant mono- and di-nucleosomes, the latter having particular potential since recent studies have highlighted the importance of linker DNA in the mechanisms of many remodelers and modifiers (Poepsel et al., 2018; Bhardwaj et al., 2020). Finally, we present a new rapid depletion approach for mammalian cells, inspired by the yeast anchor-away system (Haruki et al., 2008). In this system, a nuclear protein is tagged with a peptide that can be induced to bind a tagged endogenous ribosomal protein, which acts as an anchor to rapidly export it to the cytosol, crippling its nuclear function.

\section{STEP-BY-STEP PROCEDURES}

\section{Purification of Endogenously Tagged NuA4/TIP60 Complex (Figure 1)}

Tagging an endogenous gene to purify its encoded protein has the advantage of reflecting its physiological expression and regulation. Insertion of the small $3 \times$ FLAG- $2 \times$ Strep tag using CRISPR/Cas9 and donor DNA is efficient, does not require a selection marker, and creates very limited sequence perturbation of the $5^{\prime}$ or $3^{\prime}$ untranslated regions. NuA4/TIP60 complex is a highly conserved multisubunit complex essential for cell cycle progression, gene-specific regulation, and DNA repair (Doyon et al., 2004). Here, the E1A binding protein p400 (EP400) NuA4/TIP60 was selected for endogenous tagging as it was successfully reported to be efficient to purify the native complex (Dalvai et al., 2015). However, the tagging of many other subunits of this complex has been successfully used to purified native complex (Ikura et al., 2000; Doyon et al., 2004, 2006; Dalvai et al., 2015; Jacquet et al., 2016). The generation of endogenously tagged EP400 in K562 cells was performed essentially as described in the third protocol presented here, and was reported in Dalvai et al. (2015). In this section, we describe the protocol for TAP of $3 \times$ FLAG-2 $\times$ Strep-tagged native complexes from nuclear extracts (NEs) (Figure 1A).

\section{NE preparation from $K 562$ cells expressing endogenous $3 \times$ FLAG-2 $\times$ Strep-EP400}

\section{A. Large-scale expansion of K562 cells}

i. Grow 1-3 L of K562 cells in spinner flasks with gentle agitation in basal RPMI medium supplemented with $25 \mathrm{mM}$ HEPES-NaOH $\mathrm{pH}$ 7.4.

ii. Monitor cell growth and viability daily, carefully maintaining cultures between $2 \times 10^{5}$ and $8 \times 10^{5}$ cells $/ \mathrm{mL}$.

iii. Harvest cells at or slightly below $8 \times 10^{5}$ cells $/ \mathrm{mL}$, before they reach confluency.

iv. Pellet the cells in a preparative centrifuge $(700 \times g$, $10 \mathrm{~min}, 4^{\circ} \mathrm{C}$ ). Resuspend and pool the pellets in $50 \mathrm{~mL}$ of cold phosphate-buffered saline (PBS). Centrifuge $\left(700 \times g, 10 \mathrm{~min}, 4^{\circ} \mathrm{C}\right)$, place the pellet on ice, and immediately prepare the NE.

B. NE preparation (as previously described in Abmayr et al., 2006)

i. Wash the cell pellets by adding four packed cell volumes of hypotonic buffer (10 mM HEPES pH 7.9, $1.5 \mathrm{mM} \mathrm{MgCl}_{2}$, and $10 \mathrm{mM} \mathrm{KCl}$, with $0.2 \mathrm{mM}$ phenylmethylsulfonyl fluoride (PMSF) and $0.5 \mathrm{M}$ dithiothreitol (DTT) added just before use). Centrifuge $\left(1,900 \times g, 5 \mathrm{~min}, 4^{\circ} \mathrm{C}\right)$, remove the supernatant quickly, and resuspend well with three packed cell volumes of hypotonic buffer. Incubate on ice $10 \mathrm{~min}$.

ii. Transfer the cells to a glass Dounce homogenizer with a type $\mathrm{B}$ pestle. Homogenize by douncing 15 times, then centrifuge $\left(3,500 \times g, 10 \mathrm{~min}, 4^{\circ} \mathrm{C}\right)$.

iii. Collect the supernatant (i.e., S-100 cytoplasmic extract) and estimate the packed nuclear volume of the pellet using the gradations on the conical tube.

iv. Add half the packed nuclear volume of low salt buffer (10 mM HEPES pH 7.9, 1.5 mM MgCl, $20 \mathrm{mM} \mathrm{KCl,} \mathrm{25 \%}$ glycerol, $0.2 \mathrm{mM}$ ethylenediaminetetraacetic acid (EDTA), with $0.2 \mathrm{mM}$ PMSF and 0.5 M DTT added fresh) and resuspend well with gentle vortexing. Then, extract the soluble proteins by adding half the packed nuclear volume of high salt buffer (10 mM HEPES pH 7.9, $1.5 \mathrm{mM} \mathrm{MgCl}_{2}$, $1.2 \mathrm{M} \mathrm{KCl}, 25 \%$ glycerol, and $0.2 \mathrm{mM}$ EDTA, with 0.2 $\mathrm{mM}$ PMSF and 0.5 M DTT added fresh) dropwise with gentle vortexing.

v. Dounce twice using a Dounce homogenizer with a type B pestle and incubate on a nutator for $30 \mathrm{~min}$ at $4^{\circ} \mathrm{C}$.

vi. Pellet the extracted nuclei by ultracentrifugation $\left(100,000 \times g, 1 \mathrm{~h}, 4^{\circ} \mathrm{C}\right)$. Quickly transfer the supernatant (i.e., the NE) to a new Falcon tube.

vii. Snap freeze the $\mathrm{NE}$ in liquid nitrogen and store at $-80^{\circ} \mathrm{C}$.

2. TAP of EP400 (as described in Doyon and Côté, 2016)

i. Thaw the $\mathrm{NE}^{*}$ on ice, adjust to $0.1 \%$ Tween-20 (using a $10 \%$ stock), and centrifuge $\left(40,000 \times g, 1 \mathrm{~h}, 4^{\circ} \mathrm{C}\right)$. 


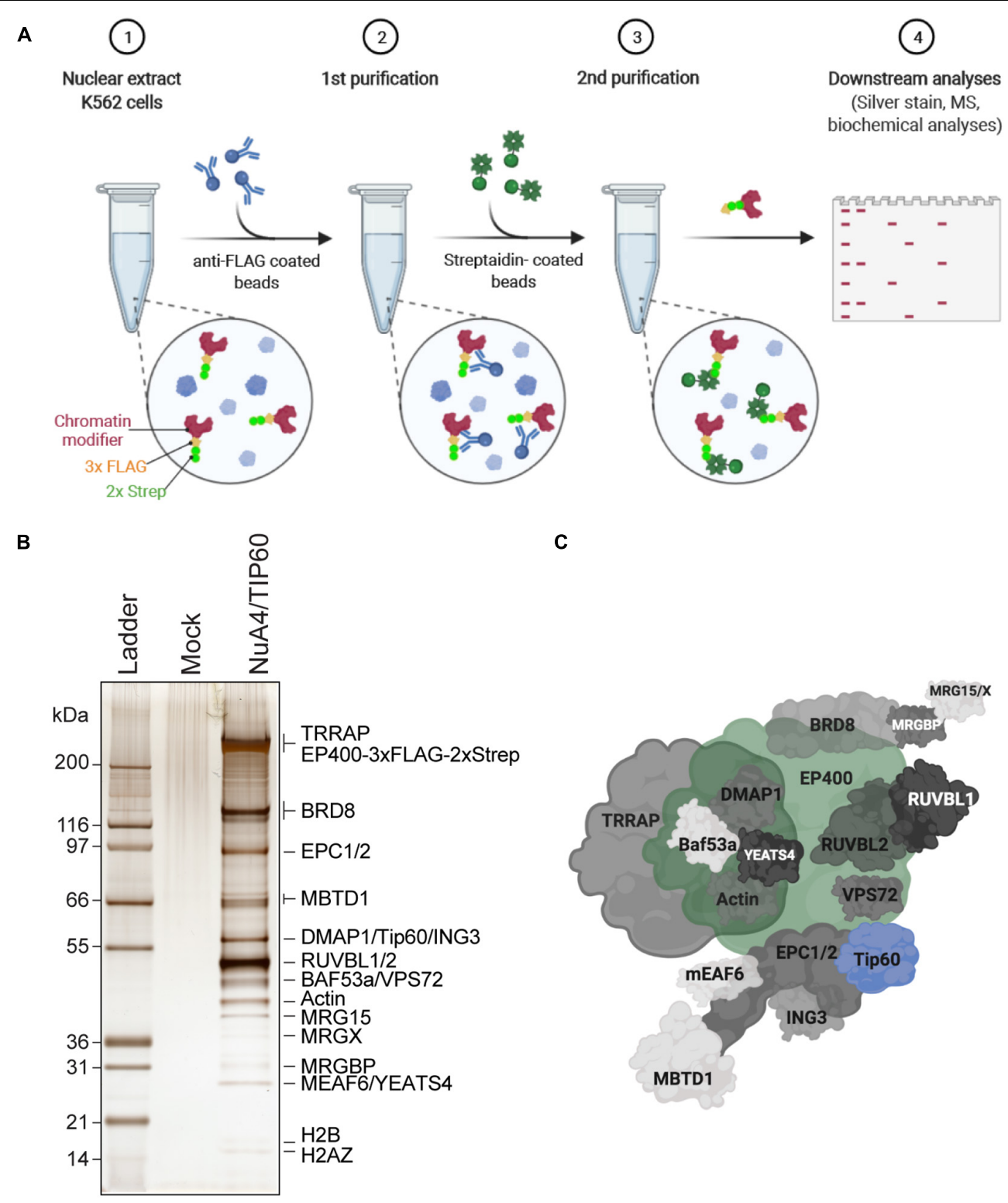

FIGURE 1 | Purification of endogenously tagged native chromatin modifying enzymes (A) TAP. Step 1: Nuclear extracts are isolated from engineered K562 cell lines (here, C-terminally $3 \times$ FLAG-2 $\times$ Strep-tagged endogenous EP400 was used as an example). Step 2: FLAG-Strep-tagged proteins are immunoprecipitated using anti-FLAG-coated beads and eluted with $3 \times$ FLAG peptides. Step 3: Eluted FLAG-Strep-tagged proteins are isolated using streptavidin-coated beads and eluted with biotin. Step 4: Purified FLAG-Strep-tagged proteins are either analyzed by silver staining and/or MS, or directly used in biochemical assays. Created with BioRender.com. (B) Silver-stained purified NuA4/TIP60 native complex after TAP of $3 \times$ FLAG-2 $\times$ Strep-EP400. K562 cells expressing the $3 \times$ FLAG-2 $\times$ Strep tag alone (mock) were used as a control purification. (C) Schematic representation of the NuA4/TIP60 complex. The TIP60 subunit, which encompasses the acetyltransferase activity of the complex, is colored in blue and the tagged subunit EP400 is colored in green. Created with BioRender.com.

ii. Preclear the NE using $250 \mu \mathrm{L}$ Sepharose CL-6B resin prewashed with PBS and equilibrated with TAP buffer $(20$ mM HEPES-KOH pH 7.9, $300 \mathrm{mM} \mathrm{KCl,} 1.5 \mathrm{mM} \mathrm{MgCl}_{2}$, $0.2 \mathrm{mM}$ EDTA, and $10 \%$ glycerol, with $10 \mathrm{mM}$ sodium butyrate, $10 \mathrm{mM} \beta$-glycerophosphate, $1 \mathrm{mM}$ PMSF, $5 \mathrm{mM}$ NaF, $100 \mu \mathrm{M}$ orthovanadate, $2 \mu \mathrm{g} / \mathrm{mL}$ leupeptin, $2 \mu \mathrm{g} / \mathrm{mL}$ pepstatin, and $5 \mu \mathrm{g} / \mathrm{mL}$ aprotinin added fresh) in a $10 \mathrm{~mL}$ Poly-Prep chromatography column. Collect the precleared $\mathrm{NE}$ in a $15 \mathrm{~mL}$ tube. iii. Add $250 \mu \mathrm{L}$ anti-FLAG M2 affinity beads to the precleared $\mathrm{NE}$ and incubate for $2 \mathrm{~h}$ at $4^{\circ} \mathrm{C}$ with rotation.

iv. Transfer to a $10 \mathrm{~mL}$ Poly-Prep chromatography column, harvest the flowthrough (FLAG-FT), and pass it through the column again. Wash the beads with 40 column volumes (CVs) of TAP buffer, then 40 CVs of TAP wash buffer \#1 (20 mM HEPES-KOH pH 7.9, 300 mM KCl, 0.1\% Tween-20, and $10 \%$ glycerol, with $1 \mathrm{mM}$ DTT, $10 \mathrm{mM}$ sodium butyrate, 10 mM $\beta$-glycerophosphate, $1 \mathrm{mM}$ PMSF, $5 \mathrm{mM} \mathrm{NaF}, 100 \mu \mathrm{M}$ 
orthovanadate, $2 \mu \mathrm{g} / \mathrm{mL}$ leupeptin, $2 \mu \mathrm{g} / \mathrm{mL}$ pepstatin, and $5 \mu \mathrm{g} / \mathrm{mL}$ aprotinin added fresh), followed by $40 \mathrm{CVs}$ of TAP wash buffer \#2 (20 mM HEPES-KOH pH 7.9, $150 \mathrm{mM} \mathrm{KCl}$, $0.1 \%$ Tween-20, and 10\% glycerol, with $1 \mathrm{mM}$ DTT, $10 \mathrm{mM}$ sodium butyrate, $10 \mathrm{mM} \beta$-glycerophosphate, $1 \mathrm{mM}$ PMSF, $5 \mathrm{mM} \mathrm{NaF}, 100 \mu \mathrm{M}$ orthovanadate, $2 \mu \mathrm{g} / \mathrm{mL}$ leupeptin, $2 \mu \mathrm{g} / \mathrm{mL}$ pepstatin, and $5 \mu \mathrm{g} / \mathrm{mL}$ aprotinin added fresh).

v. Transfer the beads in a $1.5 \mathrm{~mL}$ Eppendorf tube. Use TAP wash buffer \#2 to rinse the column and collect all the beads. Centrifuge $\left(239 \times g, 5 \mathrm{~min}, 4^{\circ} \mathrm{C}\right)$ and carefully remove the supernatant.

vi. Elute the complex with $2.5 \mathrm{CVs}$ of TAP wash buffer \#2 supplemented with $200 \mu \mathrm{g} / \mathrm{mL} 3 \times$ FLAG peptide for $1 \mathrm{~h}$ at $4^{\circ} \mathrm{C}$ on a rotator.

vii. Centrifuge $\left(250 \times g, 5 \mathrm{~min}, 4^{\circ} \mathrm{C}\right)$ and carefully transfer the supernatant into a Micro Bio-Spin column placed in a $2 \mathrm{~mL}$ microcentrifuge tube. Centrifuge $(250 \times \mathrm{g}, 1 \mathrm{~min}$, $4^{\circ} \mathrm{C}$ ) to collect the eluate. Collect a $15 \mu \mathrm{L}$ sample to resolve by sodium dodecyl sulfate (SDS)-polyacrylamide gel electrophoresis (PAGE; FLAG first elution).

viii. Repeat steps vi and vii.

ix. Pool the FLAG elutions and add $125 \mu \mathrm{L}$ Strep-Tactin Superflow Sepharose affinity matrix prewashed with $1 \mathrm{~mL}$ PBS followed by $1 \mathrm{~mL}$ TAP wash buffer \#2. Incubate for $1 \mathrm{~h}$ at $4^{\circ} \mathrm{C}$ on a rotator.

x. Centrifuge $\left(250 \times g, 5 \mathrm{~min}, 4^{\circ} \mathrm{C}\right)$ and remove the flowthrough.

xi. Wash the beads three times with $1 \mathrm{~mL}$ TAP wash buffer \#2.

xii. Elute the complex with $1 \mathrm{CV}$ of TAP wash buffer \#2 supplemented with $5 \mathrm{mM}$ D-biotin for $1 \mathrm{~h}$ at $4^{\circ} \mathrm{C}$ on a rotator.

xiii. Centrifuge $\left(250 \times g, 5 \mathrm{~min}, 4^{\circ} \mathrm{C}\right)$ and carefully transfer the supernatant into a Micro Bio-Spin column placed in a $2 \mathrm{~mL}$ microcentrifuge tube. Centrifuge $\left(250 \times g, 1 \mathrm{~min}, 4^{\circ} \mathrm{C}\right)$ to collect the eluate. Aliquot a $15 \mu \mathrm{L}$ sample for SDS-PAGE (biotin elution).

xiv. Repeat steps xiii and xiv.

xv. Aliquot the purified complex. Snap freeze in liquid nitrogen and keep at $-80^{\circ} \mathrm{C}$.

* NEs should always be kept on ice, and all purification steps should be performed at $4^{\circ} \mathrm{C}$ in a cold room.

3. Analysis of EP400 complex subunits by SDS-PAGE and silver staining (Figures $1 B, C$ )

i. Load $15 \mu \mathrm{L}$ of the FLAG and biotin elution fractions on a NuPage/Bolt 4-12\% Bis-Tris gel and run for $42 \mathrm{~min}$ at $200 \mathrm{~V}$ in MOPS SDS running buffer (50 mM MOPS, $50 \mathrm{mM}$ Tris, $0.1 \%$ SDS, and $1 \mathrm{mM}$ EDTA).

ii. Incubate the gel for $1 \mathrm{~h}$ in $50 \%$ methanol, then for $30 \mathrm{~min}$ in $10 \% \mathrm{MeOH} / 7 \%$ acetic acid, and finally for $30 \mathrm{~min}$ in $10 \%$ glutaraldehyde.

iii. Wash the gel at least four times for $30 \mathrm{~min}$ with ultrapure water and let it soak in water overnight.

iv. The next day, change the ultrapure water 2-3 times before staining.

v. Incubate the gel with $5 \mu \mathrm{g} / \mathrm{mL}$ DTT for $30 \mathrm{~min}$. vi. Stain the gel with $0.1 \%(\mathrm{w} / \mathrm{v})$ silver nitrate in ultrapure water for $30 \mathrm{~min}$.

vii. Rinse twice with ultrapure water.

viii. Condition the gel with two rapid washes in carbonate developing solution (283 $\mathrm{mM}$ sodium carbonate, $0.0185 \%$ formaldehyde), then incubate in exactly $160 \mathrm{~mL}$ of solution.

ix. Stop the reaction when proper staining is attained by adding $8 \mathrm{~mL}$ of $2.3 \mathrm{M}$ citric acid.

4. Sample preparation for mass spectrometry (MS) analysis

i. Load $50 \mu \mathrm{L}$ samples of the biotin elutions onto a Bolt $12 \%$ Bis-Tris gel and let run for $>1 \mathrm{~cm}$ (approximately $4 \mathrm{~min}$ ) at $200 \mathrm{~V}$ to retain all the proteins in one band.

ii. Wash the gel briefly with ultrapure water and incubate it for $30 \mathrm{~min}$ in $10 \% \mathrm{MeOH} / 7 \%$ acetic acid.

iii. Incubate the gel $\mathrm{O} / \mathrm{N}$ in Sypro Ruby gel stain.

iv. Rinse twice with ultrapure water and cut out the protein bands under UV light.

v. Rinse the bands twice with $70 \%$ acetonitrile and store the samples at $-80^{\circ} \mathrm{C}$.

\section{CHARACTERIZATION OF in vitro HISTONE ACETYLTRANFERASE (HAT) ACTIVITY (Figure 2)}

Chromatin modifiers like NuA4/TIP60 efficiently acetylate histone tails as well as purified histones; however, the use of oligonucleosomes purified from cell nuclei (Côté et al., 1995; Utley et al., 1996) or reconstituted from recombinant histones revealed different specificities toward these substrates (Lalonde et al., 2014). In this section, we describe a robust method used to reconstitute mono- and dinucleosomes from recombinant histones purified from Escherichia coli. The method is adapted (Dyer et al., 2003) and can be used to assemble recombinant nucleosome core particles (rNCPs) containing different types of histones. Here, rNCPs were reconstituted using untagged human $\mathrm{H} 2 \mathrm{~A} / \mathrm{H} 2 \mathrm{~B}$ and Xenopus laevis $\mathrm{H} 3 / \mathrm{H} 4$. Cysteine 110 of histone $\mathrm{H} 3$ was replaced with an alanine to block undesired cysteine alkylation in assays where analogs are used to label other residues (e.g., H4 K20Cme) (Simon, 2010). Histones tagged on their $\mathrm{N}$-termini with tags such as histidine (His) or FLAG can also be used to assemble rNCPs; however, we have noted that on $\mathrm{H} 2 \mathrm{~A}$, these tags interfere with NuA4/TIP60 activity in vitro (data not shown). These observations are in line with previous studies showing that NuA4 binds the N-terminal tail of histone H2A (Huang and Tan, 2013). Here, two DNA fragments were used for reconstitution: a $151 \mathrm{bp}$ fragment that contains a single copy of the 601 DNA used to assemble mononucleosomes (Lowary and Widom, 1998; Thåström et al., 1999; Dyer et al., 2003) and a 388 bp fragment containing two copies of 601 separated by a 48-bp linker DNA to assemble dinucleosomes (Kato et al., 2017; Machida et al., 2018). Note that an array of DNA fragments can be used to reconstitute rNCPs, facilitating structural studies of nucleosome assembly (Engeholm et al., 2009; Muthurajan et al., 2016). In this section, we also describe the main steps required to assess the activity of the purified NuA4/TIP60 complex in vitro 


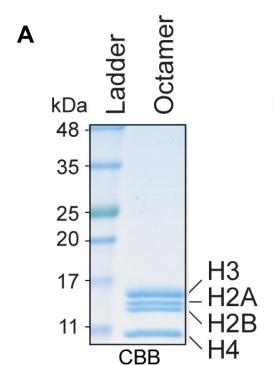

C

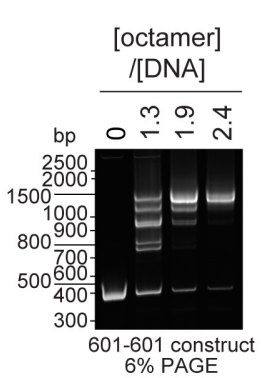

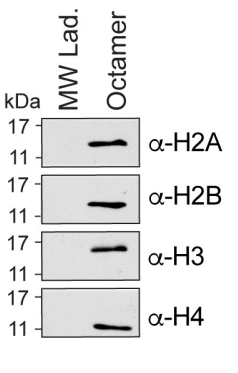

D

B

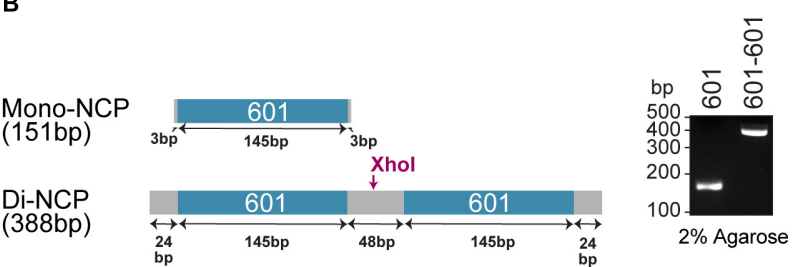

E

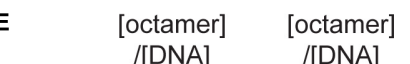

[octamer] [octamer]

$\frac{/[\mathrm{DNA}]}{601-} \frac{/[\mathrm{DNA}]}{601-}$ $601 \quad 601 \quad 601 \quad 601$

r.
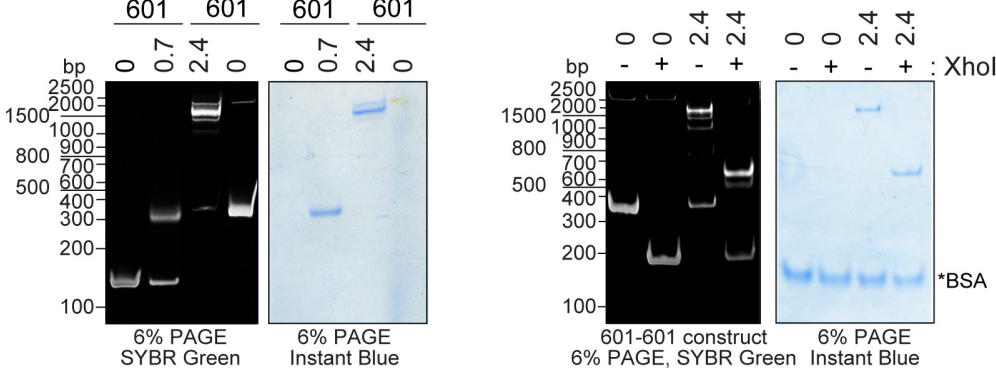

$6 \%$ PAGE, SYBR Green Instant Blue

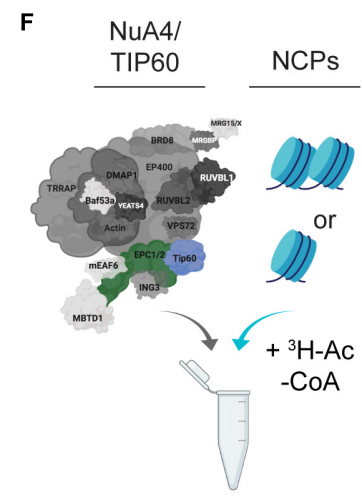

G

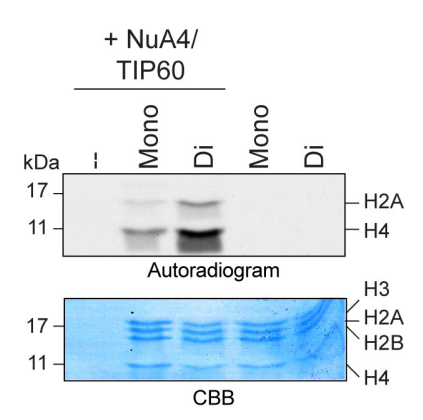

H

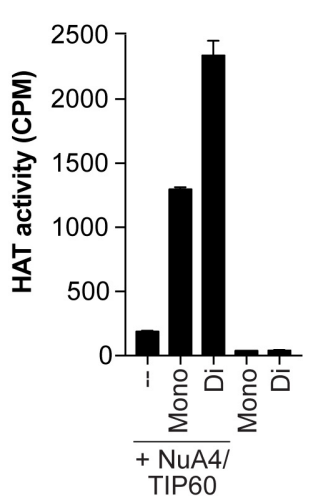

FIGURE 2 | Quantifying the HAT activity of native complexes on recombinant nucleosomes (A,B). Analysis of the octamers and 601 DNA used to reconstitute NCPs. (A) Coomassie Brilliant Blue (CBB) staining (left panel) and western blot analyses (right panel) of refolded octamers. (B) Schematic representation of the Widom 601 DNA sequence used to wrap mono- and di-NCPs (left panel). The position of the Xhol cleavage site used to validate di-NCP assembly is indicated. Purified DNA obtained from a large prep purification was resolved on a $2 \%$ agarose gel and stained with ethidium bromide (right panel). (C-E) Analysis of 200 ng of NCP reconstitution on native gels stained with either SYBR green or InstantBlue Coomassie Stain. 200 ng of DNA alone (0) is used as a control. (C) Refolding of di-NCPs using the indicated octamer:DNA ratios. (D) Mono- and di-NCPs refolded at their optimal octamer:DNA ratios. (E) Di-NCPs treated with Xhol for $1 \mathrm{~h}$. The cleaved form of the 601-601 DNA is observed at approximately 200 bp. *BSA used in the reaction. (F-H) HAT assay using NuA4/TIP60 complex purified using EPC1-tagged subunit and reconstituted NCPs. The TIP60 subunit, which encompasses the acetyltransferase activity of the complex, is colored in blue and the tagged subunit EPC1 is colored in green. Created with BioRender.com. (F) Schematic representation of the HAT assay. (G) Autoradiogram showing the HAT activity of $1 \mu L$ of purified native NuA4/TIP60 complex on histone $\mathrm{H} 2 \mathrm{~A}$ and $\mathrm{H} 4$. The gel was kept with the X-ray film at $-80^{\circ} \mathrm{C}$ for 4 days. Coomassie Brilliant Blue (CBB) staining was used to show equal loading. (H) Quantification of a representative experiment $(n=3)$. HAT reactions were spotted on P81 filters and analyzed with a scintillation counter. Error bars indicate the range between technical duplicate samples.

using gel- and liquid-based assays (Côté et al., 1995; Utley et al., 1996).

\section{Reconstitution of mono- and dinucleosome-containing rNCPs}

Histone purification (A), refolding of core histones into octamers (B), large-scale purification of 601 and 601-601
DNA (C), and nucleosome reconstitution were performed as previously described (Dyer et al., 2003).

\section{A. Histone purification}

i. On day 1, transform bacterial expression vectors for histones (human $\mathrm{H} 2 \mathrm{~A}$ and $\mathrm{H} 2 \mathrm{~B}$ in $\mathrm{pET} 15 \mathrm{~b}, X$. laevis $\mathrm{H} 3_{\mathrm{C} 110 \mathrm{~A}}$ in pET3d and $\mathrm{X}$. laevis $\mathrm{H} 4$ in pET3a) into BL21 
(DE3) competent cells and plate on lysogeny broth (LB) plates with ampicillin.

ii. On day 2, resuspend colonies and inoculate $1 \mathrm{~L}$ of LB plus $100 \mu \mathrm{g} / \mathrm{mL}$ of ampicilin. When cells reach an optical density at $600 \mathrm{~nm}$ of $0.5-0.8$, induce with $0.4 \mathrm{mM}$ isopropyl $\beta$-Dthiogalactoside (IPTG) at $37^{\circ} \mathrm{C}$. An aliquot can be taken prior to addition of IPTG as a negative control for histone induction.

iii. Pellet the induced bacteria via centrifugation $(6,000 \times g, 15$ $\left.\min , 4^{\circ} \mathrm{C}\right) 3 \mathrm{~h}\left(\mathrm{H} 2 \mathrm{~A}, \mathrm{H} 2 \mathrm{~B}\right.$, and $\left.\mathrm{H} 3{ }^{\mathrm{C} 110 \mathrm{~A}}\right)$ or $1.5 \mathrm{~h}(\mathrm{H} 4)$ postinduction, transfer the bacteria to a $50 \mathrm{~mL}$ centrifuge tube in $35 \mathrm{~mL}$ of histone wash buffer (50 mM Tris pH 7.5, $100 \mathrm{mM}$ $\mathrm{NaCl}$, and $1 \mathrm{mM}$ EDTA, with $1 \mathrm{mM}$ benzamidine and $5 \mathrm{mM}$ $\beta$-mercaptoethanol added fresh), and snap freeze in liquid nitrogen. An aliquot can be taken prior to centrifugation to monitor histone induction.

iv. To prepare inclusion bodies, thaw the bacteria in warm water and perform two rounds of freeze-thaw lysis. Add $1 \mathrm{mg} / \mathrm{mL}$ lysozyme, nutate $30 \mathrm{~min}$ at $4^{\circ} \mathrm{C}$, and sonicate until the lysate loses its viscosity. Add histone wash buffer to a total volume of $100 \mathrm{~mL}$, centrifuge $(12,000 \times g, 20$ $\min , 4^{\circ} \mathrm{C}$ ), resuspend the pellet in $75 \mathrm{~mL}$ histone wash buffer $+1 \%$ Triton $\mathrm{X}-100$, centrifuge $(12,000 \times \mathrm{g}, 20 \mathrm{~min}$, $4^{\circ} \mathrm{C}$ ), resuspend the pellet in $75 \mathrm{~mL}$ histone wash buffer, and centrifuge again $\left(12,000 \times g, 20 \mathrm{~min}, 4^{\circ} \mathrm{C}\right)$. Drain the pellet well for the next step. Cell lysates and purified proteins should be kept on ice at all times unless stated otherwise.

v. To unfold inclusion bodies, transfer the pellet to a centrifugation tube and dissolve in $260 \mu \mathrm{L}$ dimethyl sulfoxide for $30 \mathrm{~min}$ at room temperature. Mince with a spatula twice during this time. Add $8 \mathrm{~mL}$ unfolding buffer (6 $\mathrm{M}$ guanidinium $\mathrm{HCl}$ and $20 \mathrm{mM}$ Tris $\mathrm{pH} 7.5$, with $5 \mathrm{mM}$ DTT added fresh) and nutate for $1 \mathrm{~h}$ at room temperature. Centrifuge $(23,000 \times g, 10 \mathrm{~min}$, room temperature) and retain the supernatant. Rinse the pellet with $1 \mathrm{~mL}$ unfolding buffer and centrifuge again $(23,000 \times g, 10 \mathrm{~min}$, room temperature). Pool the supernatants and dialyze them in

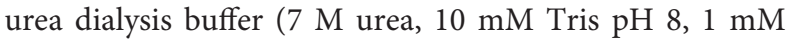
EDTA, and $100 \mathrm{mM} \mathrm{NaCl}$, with $5 \mathrm{mM} \beta$-mercaptoethanol added fresh, $2 \times 1 \mathrm{~L}$ for $3-4 \mathrm{~h}$ and $1 \times$ in $1 \mathrm{~L}$ overnight*) using dialysis tubing with a cutoff of $3.5 \mathrm{kDa}$.

vi. To purify the histones, cation exchange chromatography is used. Rinse a clean HiTrap SP HP Sepharose column with $10 \mathrm{~mL}$ of water and equilibrate with $20 \mathrm{~mL} 0.22-\mu \mathrm{m}$ filtered Buffer A (7 M urea and $20 \mathrm{mM}$ Tris $\mathrm{pH}$, with $5 \mathrm{mM} \beta$-mercaptoethanol added fresh) at $2 \mathrm{~mL} / \mathrm{min}$ using a peristaltic pump. Load the dialyzed protein sample and wash with $30 \mathrm{~mL}$ Buffer A at $1.5 \mathrm{~mL} / \mathrm{min}$. Connect the SP column to an NGC Quest 10 Plus Chromatography System, ensuring that no air bubbles enter the system, and run a linear gradient over $25 \mathrm{CV}$ of $0-100 \% 0.22-\mu \mathrm{m}$ filtered Buffer B with a flow rate of $1.5 \mathrm{~mL} / \mathrm{min}$ and a backpressure limit of $0.28 \mathrm{MPa}$. Collect $1.5 \mathrm{~mL}$ fractions and monitor the absorbance at $280 \mathrm{~nm}\left(\mathrm{~A}_{280}\right)$ and conductivity $(\mathrm{mS} / \mathrm{cm})$ during elution. Proteins will elute according to their charges, with histones usually eluting at approximately $36 \mathrm{~mL}$ and $10 \mathrm{mS} / \mathrm{cm}$. vii. Resolve eluted fractions from the peaks by $15 \%$ SDSPAGE and pool fractions containing purified histones (hH2A: 14.09 kDa, hH2B: 13.97 kDa, xH3: 15.4 kDa, xH4: $11.37 \mathrm{kDa})$. Dialyze in $2 \mathrm{mM} \beta$-mercaptoethanol in water ( $3 \times 4 \mathrm{~L}$ for $3-4 \mathrm{~h}$ and $1 \times$ in $4 \mathrm{~L}$ overnight) using dialysis tubing with a cutoff of $3.5 \mathrm{kDa}$.

viii. Centrifuge any precipitate, use $\mathrm{A}_{280}$ values to determine histone concentrations using extinction coefficients ( $\mathrm{hH} 2 \mathrm{~A}$ : 4,470 $\mathrm{M}^{-1} \mathrm{~cm}^{-1}$, hH2B: 7,450 $\mathrm{M}^{-1} \mathrm{~cm}^{-1}$, xH3: 4,470 $\mathrm{M}^{-1} \mathrm{~cm}^{-1}$, $\mathrm{xH} 4: 5,960 \mathrm{M}^{-1} \mathrm{~cm}^{-1}$ ) and lyophilize $5 \mathrm{mg}$ of dry histone per $15 \mathrm{~mL}$ centrifuge tube using a lyophilizer. Store lyophilized histones at $-80^{\circ} \mathrm{C}$.

* To reduce protein carbamylation by cyanate present in old urea, do not leave your protein in the urea buffer for more than $24 \mathrm{~h}$ and deionize the $7 \mathrm{M}$ urea solution for $1 \mathrm{~h}$ using $M B$ AG 501-X8 (D) resin prior to adding Tris, EDTA, and $\mathrm{NaCl}$.

B. Refolding of core histones into octamers

i. Unfold lyophilized histones by nutating them for $30 \mathrm{~min}$ at room temperature in $0.22-\mu \mathrm{m}$ filtered unfolding buffer (20 $\mathrm{mM}$ Tris $\mathrm{pH}$ 7.5, $7 \mathrm{M}$ guanidine-HCL, and $10 \mathrm{mM}$ DTT added fresh) to a final concentration of $\sim 2 \mathrm{mg} / \mathrm{mL}$.

ii. Combine histones in equimolar ratios in unfolding buffer to a final concentration of $\sim 1 \mathrm{mg} / \mathrm{mL}$ and dialyze in $650 \mathrm{~mL}$ refolding buffer $(10 \mathrm{mM}$ Tris $\mathrm{pH} 7.5,2 \mathrm{M} \mathrm{NaCl}$, $1 \mathrm{mM}$ EDTA, and $5 \mathrm{mM} \beta$-mercaptoethanol added fresh) in dialysis tubing with a cutoff of $3.5 \mathrm{kDa}, 2 \times 4 \mathrm{~h}$ and $1 \times$ overnight.

iii. Collect octamers in $15 \mathrm{~mL}$ centrifuge tubes, centrifuge to remove any precipitate $\left(4,000 \times g, 10 \mathrm{~min}, 4^{\circ} \mathrm{C}\right)$, and concentrate samples to $<1 \mathrm{~mL}$ using Amicon Ultra-0.5 centrifugal filter units with a cutoff of $30 \mathrm{kDa}(4,000 \times g$, $10 \mathrm{~min}, 4^{\circ} \mathrm{C}$ ).

iv. To purify refolded octamers, load the sample on a S200 Superdex 16/60 FPLC column pre-equilibrated with 1.25 $\mathrm{CV}$ of $0.22-\mu \mathrm{m}$ filtered refolding buffer using a $1 \mathrm{~mL}$ sample loop. Elute protein complexes at a flow rate of $1 \mathrm{~mL} / \mathrm{min}$ and a back-pressure limit of $0.5 \mathrm{MPa}$, and collect $2.5 \mathrm{~mL}$ fractions. Monitor the $\mathrm{A}_{280}$ during elution. Octamers eluate first, at approximately $62.5 \mathrm{~mL}$, then $\mathrm{H} 3-$ $\mathrm{H} 4$ tetramers and $\mathrm{H} 2 \mathrm{~A}-\mathrm{H} 2 \mathrm{~B}$ dimers at approximately 70 and $82 \mathrm{~mL}$, respectively.

v. Resolve eluted fractions from the peaks by $15 \%$ SDS-PAGE, pool fractions containing reconstituted octamers (the four histones should be present in equimolar ratios; Figure 2A), and dialyze in $2 \mathrm{mM} \beta$-mercaptoethanol in water using dialysis tubing with a cutoff of $3.5 \mathrm{kDa}, 3 \times 4 \mathrm{~L}$ for $3-4 \mathrm{~h}$ and $1 \times$ in $4 \mathrm{~L}$ overnight.

vi Concentrate to $\leq 15 \mathrm{mg} / \mathrm{mL}$ with an Amicon Ultra-0.5 centrifugal filter with a cutoff of $30 \mathrm{kDa}(4,000 \times \mathrm{g}, 10 \mathrm{~min}$, $4^{\circ} \mathrm{C}$ ), use the $\mathrm{A}_{280}$ to determine the concentration using an extinction coefficient (octamer: 44,700 $\mathrm{M}^{-1} \mathrm{~cm}^{-1}$ ), and store at $4^{\circ} \mathrm{C}$ for $2-3$ months or at $-20^{\circ} \mathrm{C}$ in $50 \%$ $\mathrm{v} / \mathrm{v}$ glycerol for years. Octamers stored in glycerol need to be dialyzed against fresh refolding buffer, and their 
concentration should be re-evaluated prior to use in NCP reconstitution.

* Histones are difficult to quantify accurately. To attain a better idea of the yield, resolve them by SDS-PAGE and stain with Coomassie Brilliant Blue to see if the unfolded histones look equal. Unpaired histones will precipitate during dialysis and reduce the final yield.

C. Large scale purification of 601 and 601-601 DNA (Figure 2B)

The 601-DNA (Widom DNA) (Lowary and Widom, 1998) and 601-601 DNA are obtained by digesting a $32 \times 601$ DNA plasmid (pGEM-3z/601) or E23-L48-E23 plasmid (Kato et al., 2017), which contain a repeated 147-bp nucleosome positioning sequence (Dyer et al., 2003) with EcoRV.

i. Grow DH10 $\beta$ cells transformed with a 601 or $601-601$ DNA plasmid in $3 \times 800 \mathrm{~mL}$ of LB plus $100 \mu \mathrm{g} / \mathrm{mL}$ of ampicillin at $37^{\circ} \mathrm{C}$ and purify the plasmids using a Qiagen GigaPrep kit according to the manufacturer's instructions.

ii. Digest $3 \mathrm{mg}$ of purified DNA at $37^{\circ} \mathrm{C}$ with 1,500 units of EcoRV in $15 \mathrm{~mL}$ of $1 \times \mathrm{NEB} 3$ buffer [ $100 \mathrm{mM} \mathrm{NaCl}, 50$ $\mathrm{mM}$ Tris- $\mathrm{HCl} \mathrm{pH} 7.9,10 \mathrm{mM} \mathrm{MgCl}_{2}$, and $100 \mu \mathrm{g} / \mathrm{mL}$ bovine serum albumin (BSA)] for $16 \mathrm{~h}$ to release the positioning sequence DNA. Verify complete digestion by resolving samples on a $1.5 \%$ agarose gel.

iii. Transfer the reaction in a $50 \mathrm{~mL}$ conical tube. Precipitate backbone DNA (2.5 kbp) by adding $5.1 \mathrm{~mL}$ of $40 \%$ PEG6000, $2.5 \mathrm{~mL}$ of $5 \mathrm{M} \mathrm{NaCl}$ and $0.15 \mathrm{~mL}$ of ultrapure water to reach final concentrations of 9\% PEG6000 and $500 \mathrm{mM} \mathrm{NaCl}$ in a final volume of $22.50 \mathrm{~mL}$. Incubate $4 \mathrm{~h}$ on ice, centrifuge $\left(15,000 \times g, 30 \mathrm{~min}, 4^{\circ} \mathrm{C}\right)$, carefully decant the supernatant, which contains the smaller DNA fragments (151 bp), and repeat the PEG precipitation for an additional $2 \mathrm{~h}$. Collect the supernatant after centrifugation $\left(15,000 \times g, 30 \mathrm{~min}, 4^{\circ} \mathrm{C}\right)$. Verify the purity of the DNA fragments by resolving them on a $2 \%$ agarose gel.

iv. For $11 \mathrm{~mL}$ of supernatant, precipitate the small DNA fragments by adding $27.5 \mathrm{~mL}$ of ice-cold $100 \% \mathrm{EtOH}$ and $0.5 \mathrm{~mL}$ of $5 \mathrm{M} \mathrm{NaCl}$ to reach final concentrations of $70 \% \mathrm{EtOH}$ and $200 \mathrm{mM} \mathrm{NaCl}$ in a final volume of $39 \mathrm{~mL}$. Incubate overnight at $4^{\circ} \mathrm{C}$, centrifuge $(15,000 \times g, 30$ $\min , 4^{\circ} \mathrm{C}$ ), transfer the pellet to a $1.5 \mathrm{~mL}$ Eppendorf tube in $1 \mathrm{~mL}$ of ice-cold $70 \% \mathrm{EtOH}$, centrifuge $(15,000 \times g$, $5 \mathrm{~min}, 4^{\circ} \mathrm{C}$ ), remove the supernatant, dry the pellet for $15 \mathrm{~min}$, and resuspend the pellet in $0.2 \mathrm{~mL}$ TE buffer (10 mM Tris pH 8.0, 1 mM EDTA). This method usually yields approximately $1 \mathrm{mg}$ of purified nucleosome positioning sequence DNA (Figure 2B).

D. Nucleosome reconstitution

i. Define the molar ratios required for reconstitution to minimize the presence of free DNA. Determine empirically the optimal molar ratios for mono- and dinucleosomes (here, a ratio of 0.7 and 2.4 octamers per DNA were used, respectively) (Figures 2C,D). ii. Combine $50 \mu \mathrm{g}$ of octamers $(117,760 \mathrm{~g} / \mathrm{mol})$ with either $60 \mu \mathrm{g}$ of $601 \mathrm{DNA}(151 \mathrm{bp}, 99,660 \mathrm{~g} / \mathrm{mol})$ or $45 \mu \mathrm{g}$ of 601-601 DNA (386 bp, 254,760 g/mol). Final reagent concentrations should be $2 \mathrm{M} \mathrm{KCl}$, $0.7 \mathrm{mg} / \mathrm{mL}$ DNA, 10 $\mathrm{mM}$ Tris $\mathrm{pH} 7.5,1 \mathrm{mM}$ EDTA, and $1 \mathrm{mM}$ DTT. Incubate for $30 \mathrm{~min}$ at $4^{\circ} \mathrm{C}$, transfer to a $0.5 \mathrm{~mL}$ Slide-a-Lyzer with a cutoff of $10 \mathrm{kDa}$ and dialyze against $2 \mathrm{~L}$ high salt reconstitution buffer $(2 \mathrm{M} \mathrm{KCl}, 10 \mathrm{mM}$ Tris $\mathrm{pH} 7.5$, and 1 mM EDTA, with $1 \mathrm{mM}$ DTT added fresh) with a decreasing salt gradient over $18 \mathrm{~h}$ at $4^{\circ} \mathrm{C}$. The gradient is created by constantly pumping low salt reconstitution buffer $(0.2 \mathrm{M}$ $\mathrm{KCl}, 10 \mathrm{mM}$ Tris $\mathrm{pH}$ 7.5, and $1 \mathrm{mM}$ EDTA, with $1 \mathrm{mM}$ DTT added fresh) into the $2 \mathrm{~L}$ beaker as described (Dyer et al., 2003). Transfer the samples to a fresh beaker containing $400 \mathrm{~mL}$ low salt buffer and dialyze for an additional $3 \mathrm{~h}$.

iii. Concentrate to $\leq 1 \mathrm{mg} / \mathrm{mL}$ with an Amicon Ultra-0.5 centrifugal filter with a cutoff of $100 \mathrm{kDa}(4,000 \times g, 10 \mathrm{~min}$, $4^{\circ} \mathrm{C}$ ), determine the concentration using the $\mathrm{A}_{280}$, and store at $4^{\circ} \mathrm{C}$ for 1-2 months. Recombinant nucleosomes can be stored at $-80^{\circ} \mathrm{C}$ in $5-10 \% \mathrm{v} / \mathrm{v}$ glycerol for years.

iv. Resolve $0.2 \mu \mathrm{g}$ of recombinant nucleosomes on $6 \%$ polyacrylamide gels (DNA retardation gels) in $0.2 \times \mathrm{TBE}$ (18 mM Tris, $18 \mathrm{mM}$ boric acid, and $0.4 \mathrm{mM}$ EDTA, $\mathrm{pH}$ 8.0) according to the manufacturer's instructions (Figure 2D). Samples are prepared in $1 \times$ nucleosome loading buffer $(8 \times$ : $40 \%$ sucrose, $0.1 \%$ bromophenol blue) and $0.2 \times$ TBE. DNA fragments and proteins are visualized by incubating the gel in $1 \times$ SYBR green in PBS and in InstantBlue ${ }^{\mathrm{TM}}$ Coomassie Stain, respectively, according to the manufacturers' instructions. Free 601 DNA, reconstituted mono-NCPs, 601-601 DNA, and reconstituted di-NCPs migrate at 151, 350, 350, and 1,500 $\mathrm{bp}$, respectively.

v. Digest $0.2 \mu \mathrm{g}$ of recombinant nucleosome with 5 units of XhoI (Figure 2E) in $10 \mu \mathrm{L}$ of $1 \times$ CutSmart buffer $(50 \mathrm{mM}$ potassium acetate, $20 \mathrm{mM}$ Tris-acetate $\mathrm{pH} 7.9,10 \mathrm{mM}$ $\mathrm{MgCl}_{2}$-acetate, and $100 \mu \mathrm{g} / \mathrm{mL} \mathrm{BSA}$ ) at $37^{\circ} \mathrm{C}$ for $1 \mathrm{~h}$. Resolve on $6 \%$ polyacrylamide as above. Cleaved di-NCPs migrate at $650 \mathrm{bp}$.

\section{HAT assays}

The activity of purified NuA4/TIP60 complex varies between preps. Thus, the amount of NuA4/TIP60 used in HAT assays need to be determined for each preps while doing liquid assays to obtain counts that are in the linear range of the scintillation counter.

\section{E. Reactions (Figure 2F)}

i. Perform HAT reactions in a final volume of $15 \mu \mathrm{L}$ in a $1.5 \mathrm{~mL}$ Eppendorf tube. First, combine $0.5 \mu \mathrm{g}$ of reconstituted NCPs with $1 \mu \mathrm{L}$ of purified NuA4/TIP60 complex in HAT buffer $(50 \mathrm{mM}$ Tris- $\mathrm{HCl} \mathrm{pH} 8,10 \mathrm{mM}$ sodium butyrate, $5 \%$ glycerol, and $0.1 \mathrm{mM}$ EDTA, with $1 \mathrm{mM}$ DTT added fresh). Calculate the $\mathrm{KCl}$ molarity in the reaction based on the amounts in the NCP and NuA4/TIP60 complex buffers, and add to a final 
concentration of $50 \mathrm{mM}$ if necessary. At this point, the reaction volume will be $13.75 \mu \mathrm{L}$.

ii. Incubate on ice $10 \mathrm{~min}$.

iii. Add $1.25 \mu \mathrm{L}(0.125 \mu \mathrm{Ci})$ of $\mathrm{H}^{3}$-labeled acetyl-CoA (2.1 $\mathrm{Ci} / \mathrm{mmol}$ ) and incubate at $30^{\circ} \mathrm{C}$ for $30 \mathrm{~min}$ in a water bath.

iv. At this point, the reaction can either be stopped to detect acetylated histones by SDS-PAGE (step 2B) or used in liquid HAT assays to quantify total HAT activity (step 2C).

F. Detection of acetylated histones (Figure 2G)

i. To perform SDS-PAGE, quench the HAT reaction with $5 \mu \mathrm{L}$ of $4 \times$ Laemmli sample buffer and denature the sample for $5 \mathrm{~min}$ at $95^{\circ} \mathrm{C}$.

ii. Load samples on 15 or $18 \%$ SDS-PAGE and migrate for 75$200 \mathrm{~min}$ at $160 \mathrm{~V}$, depending on the desired resolution.

iii. Stain the gel with Coomassie Brilliant Blue for $30 \mathrm{~min}$, destain four times for $20 \mathrm{~min}$ in 30\% methanol and 10\% acetic acid, and take an image of the gel.

iv. Destain overnight, incubate the gel for $60 \mathrm{~min}$ in $\mathrm{EN}^{3} \mathrm{HANCE}$, quickly rinse twice in $10 \%$ glycerol in water, and incubate for $30 \mathrm{~min}$ at room temperature. Dry the gel for $2 \mathrm{~h} 30 \mathrm{~min}$ at $60^{\circ} \mathrm{C}$ in a gel dryer, place it in an autoradiography cassette with an X-ray film, and store it at $-80^{\circ} \mathrm{C}$ for $1 \mathrm{~d}$ to several weeks before developing.

\section{G. Liquid HAT assays (Figure 2H)}

i. Microcentrifuge the reactions, then pipette them onto individual P81 phosphocellulose filter papers and air-dry for $30 \mathrm{~min}$.

ii. Wash away free $\mathrm{H}^{3}$-labeled acetyl-CoA with $50 \mathrm{mM}$ carbonate buffer pH $9.2\left(3.3 \mathrm{mM} \mathrm{Na}_{2} \mathrm{CO}_{3}\right.$ and $47.7 \mathrm{mM}$ $\mathrm{NaHCO}_{3}$ ) three times for 5 min each, then perform an extra quick rinse with acetone. Air-dry for at least $10 \mathrm{~min}$.

iii. Place each P81 paper into a scintillation vial and add $5 \mathrm{~mL}$ of EcoLite (+) Liquid Scintillation Cocktail. Measure the $\mathrm{H}^{3}$ counts [in counts per minute (CPM)] for 30 min with a scintillation counter.

\section{ESTABLISHMENT OF A MAMMALIAN (m)ANCHOR-AWAY SYSTEM (Figure 3)}

Functional studies of chromatin modifiers using knockdown/knockout approaches are well known to be often associated with undesired secondary effects on important biological processes, such as gene-specific transcription and the cell cycle progression (reviewed in Lalonde et al., 2014). To bypass this issue, we have developed a cellular system to rapidly remove a targeted protein from its usual cellular compartment based on chemically induced proximity. This system was first described as the anchor-away system in yeast (Haruki et al., 2008); however, the use of rapamycin in the system has limited its application in mammalian cells because of its toxicity, instability, and slow clearance. To adapt this method, we took advantage of the S-(+)-abscisic acid (ABA) plant stress pathway, in which the phytohormone $\mathrm{ABA}$ binds to pyrabactin resistance
(PYR)/PYR1-like (PYL)/regulatory component of ABA receptor family members (Figure 3A). This allows us to use ABA to induce proximity between the interacting complementary surface of PYL (PYLcs), fused to a protein of interest, and proteins fused to the complementary surface of $\mathrm{ABA}$ insensitive 1 (ABI1; ABI1cs) (Liang et al., 2011). We chose to fuse the ribosomal protein L13 (RPL13) to ABI1cs to take advantage of its shuttling from the nucleus to the cytoplasm like in the yeast anchor-away system. This would specifically induce the removal from the nucleus of a PYLcs-tagged protein upon ABA addition. CRISPR-Cas9 technology was used to endogenously tag the RPL13 C-terminus with ABI1cs in U2OS cells. Next, a transgene expressing PYL1cs fused to enhanced green fluorescent protein (eGFP) was integrated into the AAVS1 safe harbor locus (Hockemeyer et al., 2009; DeKelver et al., 2010; Lombardo et al., 2011), and depletion of PYLcs-eGFP from the nucleus was validated by immunofluorescence upon ABA treatment.

1. Endogenous tagging of the RPL13 C-terminus using CRISPR/Cas9 (as described in Dalvai et al., 2015)

A. Generation of single guide (sg)RNA and donor plasmid targeting RPL13 (Figure 3B)

i Endogenous tagging was performed essentially as described (Doyon and Côté, 2016). Scan your sequence using a webbased CRISPR design tool ${ }^{1}$ to identify sgRNAs that cleave no more than 30 bp away from the stop codon. For RPL13, the target site was $5^{\prime}$-CTGATTCCAAGTCCCCAGGA-3' (Figure 3B). Generate an sgRNA containing an extra G at its $5^{\prime}$ end to accommodate the transcription initiation requirements of the human U6 promoter. A BbsI restriction enzyme site is also added on each end to enable cloning into the pSpCas9(BB)-2A-Puro (pX459) V2.0 vector. Order non-phosphorylated oligonucleotides. Clone the annealed sgRNA into BbsI-digested pX459 V2.0 vector.

ii For the RPL13 donor plasmid, amplify the homology arms (left: $600 \mathrm{bp}$ and right: 1,000 bp) by polymerase chain reaction (PCR) using genomic DNA isolated from K562 cells. Be sure to mutate the PAM sequence of the sgRNA target sites if it occurs within the homology arms. Assemble using the Zero Blunt TOPO cloning kit. Introduce the ABIlcs sequence (SV-ABAactDA plasmid) (Liang et al., 2011) with a C-terminal V5 tag into the pTOPO-RPL13 donor plasmid via PCR extension overlap using a Gibson Assembly Cloning Kit.

B. Generation of isogenic U2OS cell lines expressing endogenous RPL13-ABI1cs-V5 (Figures 3C,D).

i. Maintain U2OS cells in McCoy's modified medium supplemented with $10 \%$ fetal bovine serum and penicillinstreptomycin at $37^{\circ} \mathrm{C}$ under $5 \% \mathrm{CO}_{2}$.

ii. Electroporate $1 \times 10^{6} \mathrm{U} 2 \mathrm{OS}$ cells with $2 \mu \mathrm{g}$ of the donor plasmid, $1 \mu \mathrm{g}$ of the pX459 V2.0 plasmid expressing eSpCas9, and the gRNA using an Amaxa 4D-Nucleofector

\footnotetext{
${ }^{1}$ http://crispr.mit.edu/
} 


\section{A mAnchor-away}

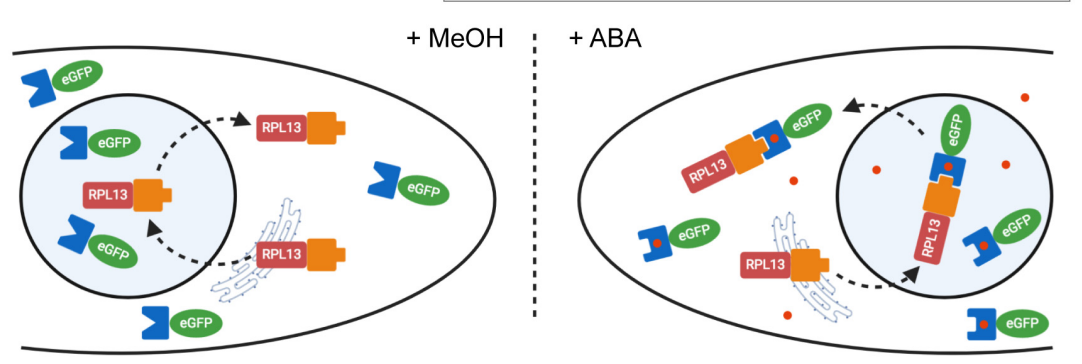

B $\operatorname{RPL} 13(3,861 b)$

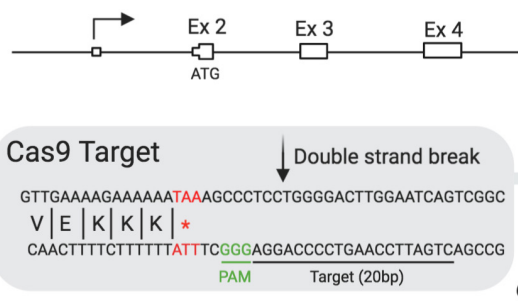

C

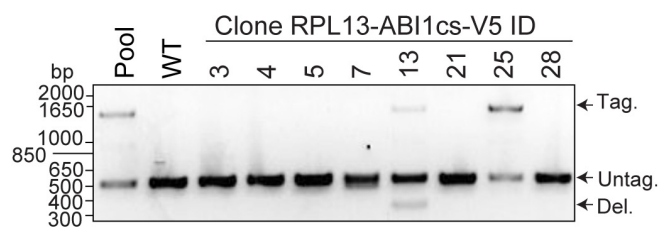

E

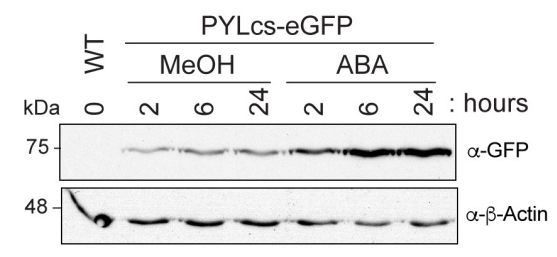

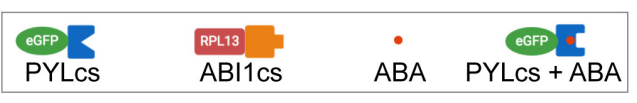

D

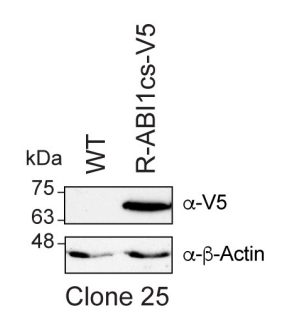

$\mathbf{F}$

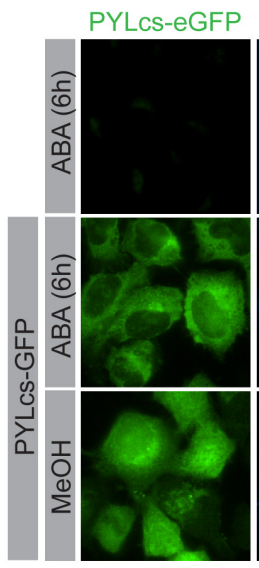

Merge

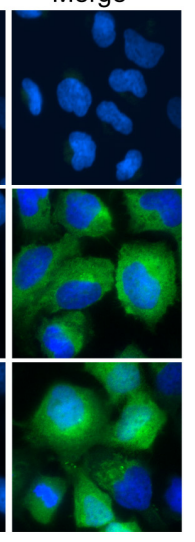

U2OS

FIGURE 3 | A mammalian anchor-away system to quickly and efficiently deplete chromatin-modifying enzymes from the nucleus (A). Schematic of ABA-induced translocation of a nuclear protein to the cytoplasm. In the absence (or presence) of ABA, the ABI1cs-RPL13 fusion protein constantly shuttles between the cytoplasm and the nucleus like most ribosomal proteins, transiting to the nucleolus to assemble ribosome particles with the ribosomal RNA and then going back to the cytoplasm. Upon the addition of ABA, the dimerization of PYLcs-tagged protein with the ABlcs-RPL13 fusion protein triggers its rapid depletion from the nucleus to the cytoplasm, as "anchored away" by the RPL13 ribosomal protein. (B) Strategy to establish U2OS cell lines expressing RPL13-ABI1cs-V5 from the endogenous locus. The RPL13 locus, the Cas9 cleavage site, and the donor construct are indicated. The sequence of the sgRNA targeting RPL13 is underlined, and the stop codon is indicated in red. HA: homology arm. (C,D) Characterization of RPL13-ABl1cs-V5 isogenic cell lines. (C) Results of an out-out PCR-base assay conducted on U2OS genomic DNA to detect ABI1cs-V5 integration at the RPL13 locus. The primers are located in the homology arms and yield a longer PCR product if ABI1cs-V5 is integrated (1,452 bp vs 510 bp for the wild-type allele). In panel (D), whole-cell extracts of wild type U2OS cells and those expressing RPL13-ABI1cs-V5 (clone \#25) were western blotted with an anti-V5 antibody to confirm RPL13-ABI1cs-V5 expression (top panel). $\beta$-actin was used as a loading control (bottom panel). (E) Whole-cell extracts of U2OS RPL13-ABI1cs-V5 cells stably expressing PYLcs-eGFP from the AAVS1 locus. Samples were collected at the indicated times following treatment with $100 \mu \mathrm{M} \mathrm{ABA}(0.1 \% \mathrm{MeOH}$ was used as a negative control). An anti-GFP antibody was used to detect PYLcs-eGFP (top panel) and $\beta$-actin was used as a loading control (bottom panel). (F) Immunofluorescence of U2OS cells expressing either RPL13-ABI1cs-V5 alone (clone \#25, as a negative control) or RPL13-ABI1cs-V5 and PYLcs-eGFP. Cells were treated with either $100 \mu \mathrm{M}$ ABA or $0.1 \% \mathrm{MeOH}$. DNA was stained with DAPI.

and an SE XL Kit, according to the manufacturer's recommendations.

iii. Expand and select clones by limiting dilution starting 3-d post-transfection in 96-well plates. iv. Extract genomic DNA with QuickExtract DNA extraction solution and amplify by PCR using the primers $5^{\prime}$-ACTTATGGCAGCGAACCTGA $-3^{\prime}$ and $5^{\prime}$ ACCTCCCCACAAGAAAACCG $-3^{\prime}$. Resolve on a $1 \%$ 
agarose gel in TAE buffer (40 mM Tris, $1 \mathrm{mM}$ EDTA, and $20 \mathrm{mM}$ glacial acetic acid) to identify the ABI1cs-V5 insertion (Figure 3C). Sequence both alleles to validate accurate gene modification and confirm the absence of indels in the non-targeted allele.

v. Confirm expression of RPL13-ABI1cs-V5 in selected clones by western blotting with an anti-V5 antibody (Figure 3D).

2. Generation of U2OS RPL13-ABI1cs-V5 cells expressing PYLcs-eGFP from the AAVS1 safe harbor locus

i. Amplify PYLcs (SV-ABAactDA plasmid) (Liang et al., 2011) by PCR and clone it in the AAVS1 Puro PGK1 $3 \times$ FLAG Twin Strep plasmid using Gibson Assembly Cloning Kit. Amplify eGFP by PCR and replace the $3 \times$ FLAG Twin Strep tag with it via Gibson cloning.

i. To introduce PYLcs-eGFP at the AAVS1 safe harbor locus via nuclease-driven targeted integration (Dalvai et al., 2015), electroporate $1 \times 10^{6}$ U2OS RPL13-ABI1cs-V5 cells with $1 \mu \mathrm{g}$ of zinc finger nuclease expression vector (Hockemeyer et al., 2009) and $4 \mu \mathrm{g}$ of the AAVS1 PYLcseGFP donor construct.

ii. Subject cells to puromycin selection for $7 \mathrm{~d}$, starting $3 \mathrm{~d}$ post-transfection.

iii. Confirm PYLcs-eGFP expression in the enriched pool following a time-course with $100 \mu \mathrm{M}$ ABA by western blotting with an anti-GFP antibody (Figure 3E).

\section{Imaging of ABA-treated RPL13-ABI1cs-V5 U2OS cells}

i. Seed enriched pools of RPL13-ABI1cs U2OS cells with AAVS1-integrated PYLcs-eGFP in 6-well plates containing autoclaved coverslips.

ii. At $60 \%$ confluency, treat cells with $100 \mu \mathrm{M}$ ABA (Liang et al., 2011) dissolved in $0.1 \%$ methanol (or $0.1 \%$ methanol as a control) for 2-24 h.

iii. Wash cells with PBS and fix them with $4 \%$ methanol-free formaldehyde for $15 \mathrm{~min}$.

iv. Wash four times with PBS and stain the nuclei using 4',6-diamidino-2-phenylindole (DAPI; $2 \mu \mathrm{g} / \mathrm{mL}$ ). Mount the coverslips on microscope slides using Fluoromount $G$ mounting medium.

v. Capture images with a Nikon $\mathrm{Ti}$ Eclipse inverted fluorescence microscope equipped with a Hamamatsu Orca ER camera using $40 \times$ or $60 \times$ objectives (Figure $3 F$ ).

\section{RESULTS AND DISCUSSION}

\section{TAP of Endogenously Tagged NuA4/TIP60 Complex}

Studies of native chromatin modifying activities require good yields of purified intact complexes to be obtained by TAP. K562 cells are an excellent model line to purify endogenously tagged chromatin remodelers, as they are permissive to genome editing and tolerate the conditions required to isolate clones. Importantly, large volumes can be cultivated as suspension cultures, which is essential to purify the yields of chromatin modifiers required to perform in vitro biochemical analyses and potentially even structural studies. Following the establishment of isogenic K562 cell lines expressing an endogenously TAPtagged component of the NuA4/TIP60 complex, the FLAG and streptavidin portions of the TAP-tag are used to purify the entire complex in a stepwise manner (Figure 1A). In this specific example, the E1A binding protein p400 (EP400) subunit was used. Nuclear extracts were prepared from K562 cells expressing tagged EP400 as well as a line expressing the $3 \times$ FLAG$2 \times$ Strep tag only (mock). Copurifying proteins were resolved by SDS-PAGE and analyzed by silver staining (Figure 1B). The high sensitivity of silver-stained gels enabled the unambiguous identification of complex subunits, which were not observed in the mock sample. Mass spectrometry analysis of the purified complex confirmed the purification of the entire NuA4/TIP60 complex (Figure 1C).

TAP-based approaches have been used to efficiently purify $\mathrm{NuA4/TIP60} \mathrm{complexes} \mathrm{using} \mathrm{an} \mathrm{array} \mathrm{of} \mathrm{tagged} \mathrm{subunits} \mathrm{(Ikura}$ et al., 2000; Doyon et al., 2004, 2006; Dalvai et al., 2015; Jacquet et al., 2016). In addition to endogenously tagged proteins, tagged chromatin modifier cDNAs integrated into a safe harbor genomic locus like AAVS1 can also be used for complex purification (Dalvai et al., 2015). The latter approach is a great alternative, as it allows the expression of near-physiological levels of the tagged protein, is straightforward, and offers high flexibility to study proteins that are difficult to tag at their endogenous locus. It can also be highly useful to compare panels of truncations and mutant proteins in an isogenic setting.

\section{Characterizing Native Chromatin-Modifying Activities in vitro}

Chromatin-modifying activities such as acetylation and methylation can be recapitulated in vitro using substrates such as peptides mimicking histone tails, purified histones (recombinant or native), rNCPs, and oligonucleosomes isolated from NEs. Of these, rNCPs provide a unique tool to study how nucleosome assembly and specific histone marks affect enzyme activity. Recently, chromatin-remodeling/modifying complexes were found to exhibit different specificity toward mononucleosomes and dinucleosomes, highlighting their higher-order structural specificity (Poepsel et al., 2018; Bhardwaj et al., 2020). We thus used rNCPs to assess whether the activity of the native NuA4/TIP60 complex is affected by the structural differences between the two types of rNCPs.

Mono- and dinucleosomes were reconstituted with octamers of core histone proteins assembled from purified human $\mathrm{H} 2 \mathrm{~A} / \mathrm{H} 2 \mathrm{~B}$ and $X$. laevis $\mathrm{H} 3 / \mathrm{H} 4$ recombinant histones (Figure 2A), and with short DNA fragments containing either one or two 601 nucleosome positioning sequences (Figure 2B) (Lowary and Widom, 1998; Kato et al., 2017). These sequences have a high affinity for histone octamers and direct nucleosome assembly with high efficiency (Lowary and Widom, 1998; Thåström et al., 1999). Mononucleosome assembly was performed as previously described (Dyer et al., 2003). For the assembly of dinucleosomes, we used the sequence designed by Kato et al. (2017), which contains an internucleosomal 
48-bp spacer that accommodates the efficient assembly of two nucleosomes on the donor DNA (Engeholm et al., 2009; Machida et al., 2018). Consistent with previous reports, we observed the formation of a predominant slower-migrating species that corresponds to dinucleosomes with an octamer:DNA molar ratio of 2.4. Nucleosome assembly was monitored by native gel electrophoresis to reveal both the DNA and protein content (Figures 2C,D). Smaller migrating species observed at lower octamer:DNA ratios with the 601-601 DNA were previously found to be due to the assembly of one nucleosome on either one of the positioning elements (Engeholm et al., 2009). The presence of two nucleosomes on the 601-601 DNA in the slower-migrating species observed was further validated by cleaving the linker DNA with XhoI (Figures 2B,E; Machida et al., 2018).

The acetyltransferase activity of purified native NuA4/TIP60 was assessed by in vitro HAT assays, in which monoor dinucleosomes were mixed with the purified complex and $\mathrm{H}^{3}$-labeled acetyl-CoA (Figure 2F). The reactions were analyzed by both SDS-PAGE and liquid HAT assays. The autoradiogram revealed that both histones $\mathrm{H} 2 \mathrm{~A}$ and $\mathrm{H} 4$ are more efficiently acetylated when recombinant dinucleosomes were used as substrate (Figure 2G). Coomassie Brilliant Blue staining confirmed that similar amounts of histones were used in each reaction. Liquid HAT assays of the same samples corroborated these results (Figure $\mathbf{2 H}$ ), which are consistent with a recent observation for the chromatin-modifier polycomb repressive complex 2, which is more active on dinucleosomes than on H3 tails or single nucleosomes (Poepsel et al., 2018). The recent development of a method to assemble rNCPs with various DNA fragments and histone variants further highlights the potential of this approach to characterize the activity of native complexes (Changolkar and Pehrson, 2003; Muthurajan et al., 2016; Sekulic and Black, 2016). For example, rNCPs can be reconstituted with different DNA fragments to study the impacts of different linker DNAs between nucleosomes and in the $5^{\prime}$ and $3^{\prime}$ ends of the template DNA (Engeholm et al., 2009). In addition, specific mutations and PTMs on residues can be engineered on canonical or variant histones prior to reconstitution, allowing very precise questions to be tested experimentally.

\section{Establishment of an Anchor-Away System for Nuclear Depletion in Mammalian Cells}

The mammalian anchor-away system allows the rapid and robust depletion of a PYLcs-tagged protein from the nucleus (Figure 3A). As long-term depletion of NuA4/TIP60 complex subunits leads to cell toxicity (Gorrini et al., 2007; Fazzio et al., 2008; Hu et al., 2009; Steunou et al., 2014; Numata et al., 2020), this system provides a great alternative to study its roles in biological processes, including DNA repair (Jacquet et al., 2016). In this example, modifier depletion immediately prior to DNA break induction would be useful to separate an acetyltransferase's transcriptional functions from its role acetylating histones surrounding the break. To establish this system in mammalian cells, we fused an ABI1cs-V5 tag to the C-terminal domain of the ribosomal protein RPL13 (homologous to the anchor used in the yeast system) using a CRISPR/Cas9-driven approach. A sgRNA targeting the $3^{\prime}$-end of exon 6 was designed to target the nuclease near the stop codon (Figure 3B). A donor molecule containing the TAP tag and homology arms for RPL13 was used to integrate the tag and delete the endogenous stop codon. Following transfection into U2OS cells, tag incorporation was detected in the pool and in two isolated clones by PCR (Figure 3C). Accurate gene modification was also confirmed by western blot analysis (Figure 3D) and by sequencing, as previously described (Dalvai et al., 2015). The PYLcs-eGFP fusion protein was integrated at the AAVS1 locus in U2OS-RPL13ABI1cs-V5 clone 25, and its expression was confirmed by western blot analysis following the addition of $\mathrm{ABA}$ (or $\mathrm{MeOH}$ as a negative control; Figure $3 \mathrm{E}$ ). Using immunofluorescence, we observed that adding ABA triggered the nuclear exclusion of eGFP $6 \mathrm{~h}$ after treatment (Figure 3F). Interestingly, the PYLcseGFP fusion was less abundant by western blot before ABA addition, suggesting that the fusion is expressed at low levels and stabilized upon complexing with RPL13-ABIcs-V5 (Figure 3D). Although these results are promising, further experiments will be required to validate that the fusion between PYLc and a ribosomal protein can efficiently deplete subunits of chromatinmodifying enzymes from the nucleus, to establish the kinetics of this process and to determine if the fusion impact the endogenous function of RPL13. The fact that we were unable to isolate a clone with homozygous tagged RPL13 (Figure 3C) raises a concern about the impact of the fusion on the cellular function of the protein. The main advantage of this system compared to other systems based on proteasome degradation (AID/Tir1 and dTAG approaches (Nabet et al., 2018; Nishimura et al., 2020; Yesbolatova et al., 2020) is that the recovery of essential nuclear protein should be faster in the absence of the drug as no degradation is involved. It is thus expected that it will have less impact on cellular fitness during experiments. Nonetheless, our results provide proof of concept of the mammalian anchoraway system's great potential to enable temporal examination of the specific functions of essential chromatin modifiers.

\section{CONCLUSION}

The detailed step-by-step protocols provided here will be helpful to researchers interested in rapidly characterizing native chromatin modifying complexes. Of course, the enzymatic assays used will differ depending on the PTM deposited, and NCP composition should be modified depending on the presumed target or hypothesis being tested (e.g., H3.3 variants vs H3.1, H2A.Z/H2A.X vs H2A). Streamlining these approaches within research teams will greatly expand the experimental angles available to address scientific questions about chromatin-based molecular mechanisms.

\section{MATERIALS AND EQUIPMENT}

\section{Reagents}

E23-L48-E23 plasmid (Kato et al., 2017) 
$3 \times$ FLAG peptide (Sigma, Cat. No. F4799)

AAVS1 Puro PGK1 $3 \times$ FLag Twin Strep Plasmid (Addgene, Cat. No. 68375)

Abscisic acid (Sigma, Cat. No. 5.30339)

Acetic acid (Anachemia, Cat. No. 000598-460)

Acetonitrile (Sigma, Cat. No. 271004)

Agar A (BioBasic, Cat. No. FB0010)

Ampicillin (Bioshop, cat. No. AMP201.100)

Anti-FLAG M2 affinity beads (Sigma, Cat. No. F1804)

Anti-GFP (Roche, Cat. No. 11814460001)

Anti-V5 antibody (Abcam, Cat. No. SV5-Pk1)

Aprotinin (Sigma, Cat. No. A3886)

BbsI (NEB, Cat. No. R0539)

Benzamidine hydrochlorate hydrate (Sigma, Cat. No. B6506)

$\beta$-mercaptoethanol (Sigma, Cat. No. M3148)

$\beta$-glycerophosphate (Sigma, Cat. No. G9422)

Bolt 4-12\% Bis-Tris gels (Thermo Fisher Scientific, Cat. No. NW04120BOX)

Bolt 12\% Bis-Tris gels (Thermo Fisher Scientific, Cat. No. NW00122BOX)

Boric acid (Sigma, Cat. No. B6768)

Bromophenol blue (Bioshop, Cat. No. BRO222)

Citric acid (Sigma, Cat. No. 251275)

Coomassie Brilliant Blue (Bioshop, Cat. No. CBB555)

Coverslips (FisherBrand, Cat. No. 12541B)

CutSmart Buffer (NEB, Cat. No. B7204S)

D-Biotin (ThermoFisher, Cat. No. B20656)

DH10ß (Thermofisher, Cat. No. EC0113)

Dimethyl sulfoxide (Sigma, Cat. No. D8418)

DNA retardation gel (Life Technology, Cat. No. EC6365BOX)

DTT (Bioshop, Cat. No. DTT002)

EcoRV (NEB, Cat. No. R3195L)

EDTA (Sigma, Cat. No. E5134)

EN3HANCE solution (PerkinElmer, Cat. No. 6NE9701)

Ethanol, 100\% (Commercial Alcohols, Cat. No. P016EAAN)

Fetal bovine serum (ThermoFisher, Cat. No. 12483020)

Filter paper - P81 (Sigma, Cat. No. Z742570)

Fluoromount G (eBioscience, Cat. No. 00-4958-02)

Formaldehyde (Sigma, Cat. No. 252549)

Gibson Assembly kit (NEB, Cat. No. E5510S)

Glutaraldehyde (Sigma, Cat. No. G6403)

Glycerol (Bioshop, Cat. No. GLY001)

Guanidinium-HCl (BioBasic, Cat. No. GB0242)

$\mathrm{H}^{3}$-labeled acetyl-CoA (PerkinElmer Life Sciences, cat. No.

NET290050UC)

HEPES (Bioshop, Cat. No. HEP001.1)

HEPES, $1 \mathrm{M}$, for cell culture (Life Technologies, Cat. No. 15630080)

HiTrap SP HP Sepharose columns (GE Healthcare, Cat. No. 45-100-294)

InstantBlue ${ }^{\mathrm{TM}}$ Coomassie Stain (Bioshop, Cat. No. CBB555.25)

Isopropyl $\beta$-D-thiogalactoside (Sigma, Cat. No. I6758-10G)

K562 cells (ATCC, Cat. No. CCL-243)
$\mathrm{KCl}$, reagent grade (Bioshop, Cat. No. POC308)

Leupeptin (Sigma, Cat. No. 78435)

EcoLite (+) Liquid Scintillation Cocktail (MP Biomedicals,

Cat. No. 0188247504)

Lysozyme from chicken egg (Sigma, Cat. No. L6876)

MB AG 501-X8 (D) resin (BioRad, Cat. No. 1436425)

McCoy's Modified Medium (ThermoFisher, Cat. No. 16600108)

Methanol (Fisher Chemical, Cat. No. A412)

Methanol Free 16\% Formaldehyde (ThermoFisher, Cat. No. 28908)

$\mathrm{MgCl}_{2}$ ACS reagent grade (Bioshop, Cat. No. MAG510)

Microscope slides (FisherBrand, Cat. No. 22-034-486)

MOPS (Sigma, Cat. No. M3183)

$\mathrm{Na}_{2} \mathrm{CO}_{3}$ (Sigma, Cat. No. 451614)

$\mathrm{NaCl}$ (Bioshop, Cat. No. SOD001.5)

$\mathrm{NaF}$ (Sigma, Cat. No. 201154)

$\mathrm{NaHCO}_{3}$ (Sigma, Cat. No. S6014)

Orthovanadate (Sigma, Cat. No. S6508)

P81 phosphocellulose filter paper (Sigma, Cat. No. Z742570)

pGEM-3z/601 (Addgene, Cat. No. 26656)

PEG6000 (Cederlane, Cat. No. 8.07491.1000)

Penicillin-Streptomycin (ThermoFisher, Cat. No. 15140122)

Pepstatin A (Sigma, Cat. No. P5318)

Pet15b vector (EDM Millipore, Cat. No. 69661)

Pet28a Synthetic Human H2A.1 (Addgene, Cat. No. 42634)

Pet28a Human H2B.1 (Addgene, Cat. No. 42630)

Pet3d Xenopus $\mathrm{H} 3_{\mathrm{C} 110 \mathrm{~A}}$ and Pet3a Xenopus $\mathrm{H} 4$ plasmids (a kind gift from Cheryl Arrowsmith)

PMSF (Thermo Fisher Scientific, Cat. No. 36978)

pSpCas9(BB)-2A-Puro (pX459) V2.0 vector (Addgene, Cat. No. 62988)

Puromycin (Sigma, Cat. No. P8833)

Qiagen GigaPrep kit (Qiagen, Cat. No. 12191)

QuickExtract DNA extraction solution (Epicentre, Cat. No. QE09050)

RPMI medium (Life Technologies, Cat. No. 21870-092)

Sepharose CL-6B resin (Sigma, Cat. No. CL-6B-200)

SE XL Kit, nucleofection (Lonza, Cat. No. V4LC-2020)

Silver nitrate (Sigma, Cat. No. S8157)

Sodium butyrate (Sigma, Cat. No. B5887)

Sodium carbonate (Sigma, Cat. No. 451614)

Strep-Tactin Superflow Sepharose affinity matrix (IBA, Cat No. 2-1206-010)

Sucrose, biotechnology grade (Bioshop, Cat. No. SUC700)

SV-ABAactDA plasmid (Addgene, Cat. No. 38247)

SYBR green (ThermoFisher, Cat. No. S7563)

Sypro $^{\text {TM }}$ Ruby protein gel stain (Bio-Rad, Cat. No. 1703125)

Tris base (Bioshop, Cat. No. TRS001.5)

Triton X-100 (BioBasic, Cat. No. TB0198)

Tryptone powder (BioBasic, Cat. No. G211)

Tween-20 (Bioshop, Cat. No. TWN508)

U2OS cells (ATCC, HTB-96)

Urea, reagent grade (Bioshop, Cat. No. URE002) 
Yeast extract (BioBasic, Cat. No. G0961)

Zero Blunt pTOPO cloning kit (Life Technology, Cat. No. 450245)

\section{Equipment}

Amicon Ultra-0.5 centrifugal filter units (Millipore, Cat. No. UFC503024)

Bioruptor (Diagenode)

Dounce homogenizer with a type B pestle (Thomas Scientific, Cat. No. 1229H80)

Dialysis tubing with a cut off of $3.5 \mathrm{kDa}$ (Thermo Scientific, Cat. No. REF68035)

Electrophoresis and blotting apparatus (Biorad, Cat. Nos. 1658001FC and 1703930)

Labconco FreeZone 1 Liter Benchtop Freeze Dry System (Cat. No. 7740020)

LS 6500 Multi-purpose Scintillation Counter (Beckman Coulter)

Nikon Ti Eclipse fluorescence microscope with a Hamamatsu Orca ER camera

NGC Scout 10 Plus and fractionator (BioRad)

Micro Bio-Spin columns (BioRad, Cat. No. 7326204)

Nutator

Optima LE-80K Ultracentrifuge (Beckman-Coulter)

Peristaltic pump (Buchler Instruments Polystaltic Pump)

Poly-Prep chromatography columns (Bio-Rad, Cat. No. 7311550)

S200 HiLoad 16/600 Superdex FPLC columns (GE Healthcare, Cat. No. 28-9893-35)

Slide-A-Lyzer $0.5 \mathrm{~mL}$ with a cut off of $10 \mathrm{kDa}$ (Life Technology, Cat. No. 66383)

Scintillation vials (Fisher, Cat. No. 03-337-20)

Sorvall LYNX 4000 Superspeed Centrifuge and tubes (Thermo Scientific)

Spinner Flasks, 3L (Fisher, Cat. No. 10203E)

UV spectrophotometer (Nanodrop One ${ }^{c}$, Thermo Scientific)

Water bath

\section{Solutions}

\begin{tabular}{|c|c|}
\hline Buffer A & $\begin{array}{l}7 \mathrm{M} \text { urea, } 20 \mathrm{mM} \text { Tris } \mathrm{pH} 8, \text { add } 5 \mathrm{mM} \\
\beta \text {-mercaptoethanol fresh (just before use) }\end{array}$ \\
\hline Buffer B & $\begin{array}{l}7 \mathrm{M} \text { urea, } 20 \mathrm{mM} \text { Tris } \mathrm{pH} 8,1 \mathrm{M} \mathrm{NaCl} \text {, add } \\
5 \mathrm{mM} \beta \text {-mercaptoethanol fresh }\end{array}$ \\
\hline Carbonate developing solution & $\begin{array}{l}283 \mathrm{mM} \text { sodium carbonate, } 0.0185 \% \\
\text { formaldehyde }\end{array}$ \\
\hline CutSmart buffer & $\begin{array}{l}50 \mathrm{mM} \text { potassium acetate, } 20 \mathrm{mM} \text { Tris-acetate } \\
\mathrm{pH} 7.9,10 \mathrm{mM} \mathrm{MgCl}_{2} \text {-acetate, } 100 \mu \mathrm{g} / \mathrm{mL} \\
\text { BSA }\end{array}$ \\
\hline HAT buffer & $\begin{array}{l}50 \mathrm{mM} \text { Tris- } \mathrm{HCl} \mathrm{pH} 8,10 \mathrm{mM} \text { sodium butyrate, } \\
5 \% \text { glycerol, } 0.1 \mathrm{mM} \text { EDTA, add } 1 \mathrm{mM} \text { DTT } \\
\text { fresh }\end{array}$ \\
\hline High salt buffer & $\begin{array}{l}10 \mathrm{mM} \text { HEPES pH 7.9, } 1.5 \mathrm{mM} \mathrm{MgCl}_{2}, 1.2 \mathrm{M} \\
\mathrm{KCl}, 25 \% \text { glycerol, } 0.2 \mathrm{mM} \text { EDTA, add } 0.2 \mathrm{mM} \\
\text { PMSF and } 0.5 \mathrm{mM} \text { DTT fresh }\end{array}$ \\
\hline
\end{tabular}

High salt reconstitution buffer

Histone wash buffer

Hypotonic buffer

Low salt buffer

Low salt reconstitution buffer

NEB3 buffer

Nucleosome loading buffer $(8 x)$ Refolding buffer

Running buffer

TAE buffer

TAP buffer

TAP wash buffer \#1

TAP wash buffer \#2

$\operatorname{TBE}(0.2 \times)$

Unfolding buffer

Urea dialysis buffer
MOPS SDS running buffer

$2 \mathrm{M} \mathrm{KCl}, 10 \mathrm{mM}$ Tris $\mathrm{pH}$ 7.5, 1 mM EDTA, add $1 \mathrm{mM}$ DTT fresh

$50 \mathrm{mM}$ Tris pH 7.5, $100 \mathrm{mM} \mathrm{NaCl}, 1$ mM EDTA, add $1 \mathrm{mM}$ benzamidine and $5 \mathrm{mM}$ $\beta$-mercaptoethanol fresh

10 mM HEPES pH 7.9, $1.5 \mathrm{mM} \mathrm{MgCl}_{2}, 10 \mathrm{mM}$ $\mathrm{KCl}$, add $0.2 \mathrm{mM}$ PMSF and $0.5 \mathrm{mM}$ DTT fresh 10 mM HEPES pH 7.9, 1.5 mM MgCl 2,20 mM $\mathrm{KCl}, 25 \%$ glycerol, $0.2 \mathrm{mM}$ EDTA, add $0.2 \mathrm{mM}$ PMSF and 0.5 M DTT fresh

0.2 M KCl, $10 \mathrm{mM}$ Tris pH 7.5, 1 mM EDTA, add $1 \mathrm{mM}$ DTT fresh

$50 \mathrm{mM}$ MOPS, $50 \mathrm{mM}$ Tris, 0.1\% SDS, 1 mM EDTA

$100 \mathrm{mM} \mathrm{NaCl}, 50$ mM Tris- $\mathrm{HCl} \mathrm{pH}$ 7.9, 10 mM $\mathrm{MgCl}_{2}, 100 \mu \mathrm{g} / \mathrm{mL} \mathrm{BSA}$

40\% sucrose, $0.1 \%$ bromophenol blue

$10 \mathrm{mM}$ Tris $\mathrm{pH}$ 7.5, $2 \mathrm{M} \mathrm{NaCl}, 1 \mathrm{mM}$ EDTA, add $5 \mathrm{mM} \beta$-mercaptoethanol fresh

$25 \mathrm{mM}$ Tris, $50 \mathrm{mM}$ glycine, 0.1\% SDS

$40 \mathrm{mM}$ Tris, $1 \mathrm{mM}$ EDTA, $20 \mathrm{mM}$ glacial acetic acid

20 mM HEPES-KOH pH 7.9, 300 mM KCl, $1.5 \mathrm{mM} \mathrm{MgCl}_{2}, 0.2 \mathrm{mM}$ EDTA, 10\% glycerol, add $10 \mathrm{mM}$ sodium butyrate, $10 \mathrm{mM}$ $\beta$-glycerophosphate, $1 \mathrm{mM}$ PMSF, $5 \mathrm{mM} \mathrm{NaF}$, $100 \mu \mathrm{M}$ orthovanadate, $2 \mu \mathrm{g} / \mathrm{mL}$ leupeptin, 2 $\mu \mathrm{g} / \mathrm{mL}$ pepstatin, and $5 \mu \mathrm{g} / \mathrm{mL}$ aprotinin fresh 20 mM HEPES-KOH pH 7.9, 300 mM KCl, $0.1 \%$ Tween-20, 10\% glycerol, add 1 mM DTT, $10 \mathrm{mM}$ sodium butyrate, $10 \mathrm{mM}$ $\beta$-glycerophosphate, $1 \mathrm{mM}$ PMSF, $5 \mathrm{mM} \mathrm{NaF}$, $100 \mu \mathrm{M}$ orthovanadate, $2 \mu \mathrm{g} / \mathrm{mL}$ leupeptin, 2 $\mu \mathrm{g} / \mathrm{mL}$ pepstatin, and $5 \mu \mathrm{g} / \mathrm{mL}$ aprotinin fresh 20 mM HEPES-KOH pH 7.9, 150 mM KCl, 0.1\% Tween-20, 10\% glycerol, add 1 mM DTT, $10 \mathrm{mM}$ sodium butyrate, $10 \mathrm{mM}$ $\beta$-glycerophosphate, $1 \mathrm{mM}$ PMSF, $5 \mathrm{mM} \mathrm{NaF}$, $100 \mu \mathrm{M}$ orthovanadate, $2 \mu \mathrm{g} / \mathrm{mL}$ leupeptin, 2 $\mu \mathrm{g} / \mathrm{mL}$ pepstatin, and $5 \mu \mathrm{g} / \mathrm{mL}$ aprotinin fresh $18 \mathrm{mM}$ Tris, $18 \mathrm{mM}$ boric acid, $0.4 \mathrm{mM}$ EDTA, $\mathrm{pH} 8.0$

$20 \mathrm{mM}$ Tris $\mathrm{pH}$ 7.5, $7 \mathrm{M}$ guanidine-HCL, add $10 \mathrm{mM}$ DTT fresh

$7 \mathrm{M}$ urea, $10 \mathrm{mM}$ Tris $\mathrm{pH} 8,1 \mathrm{mM}$ EDTA, $100 \mathrm{mM} \mathrm{NaCl}$, add $5 \mathrm{mM}$ $\beta$-mercaptoethanol fresh.

\section{DATA AVAILABILITY STATEMENT}

The original contributions presented in the study are included in the article/supplementary material, further inquiries can be directed to the corresponding author/s.

\section{AUTHOR CONTRIBUTIONS}

AF-T and JC conceived the original idea and supervised the project. MG, CL, XC, and FD-G performed initial protocol optimization. MG and CL performed the experimental work presented in this manuscript. AF-T and JC wrote the manuscript 
with contributions from MG and CL. All authors contributed to the article and approved the submitted version.

\section{FUNDING}

This research was funded in part by the Natural Sciences and Engineering Research Council of Canada (NSERC

\section{REFERENCES}

Abmayr, S. M., Yao, T., Parmely, T., and Workman, J. L. (2006). Preparation of nuclear and cytoplasmic extracts from mammalian cells. Curr. Protocols Mol. Biol. Chapter 12:Unit12.1. doi: 10.1002/0471142727.mb1201s75

Allis, C. D., and Jenuwein, T. (2016). The molecular hallmarks of epigenetic control. Nat. Rev. Genet. 17:487. doi: 10.1038/nrg.2016.59

Bhardwaj, S. K., Hailu, S. G., Olufemi, L., Brahma, S., Kundu, S., Hota, S. K., et al. (2020). Dinucleosome specificity and allosteric switch of the ISW1a ATPdependent chromatin remodeler in transcription regulation. Nat. Commun. 11:5913. doi: 10.1038/s41467-020-19700-1

Brien, G. L., Valerio, D. G., and Armstrong, S. A. (2016). Exploiting the epigenome to control cancer-promoting gene-expression programs. Cancer Cell 29, 464476. doi: 10.1016/j.ccell.2016.03.007

Changolkar, L. N., and Pehrson, J. R. (2003). Histone MacroH2A purification and nucleosome reconstitution. Methods Enzymol. 375, 228-238. doi: 10.1016/ S0076-6879(03)75015-0

Côté, J., Utley, R. T., and Workman, J. L. (1995). Basic analysis of transcription factor binding to nucleosomes. Methods Mol. Genet. 6, 108-128. doi: 10.1016/ S1067-2389(06)80009-9

Dalvai, M., Loehr, J., Jacquet, K., Huard, C. C., Roques, C., Herst, P., et al. (2015). A scalable genome-editing-based approach for mapping multiprotein complexes in human cells. Cell Rep. 13, 621-633. doi: 10.1016/j.celrep.2015.09.009

DeKelver, R. C., Choi, V. M., Moehle, E. A., Paschon, D. E., Hockemeyer, D., Meijsing, S. H., et al. (2010). Functional genomics, proteomics, and regulatory DNA analysis in isogenic settings using zinc finger nuclease-driven transgenesis into a safe harbor locus in the human genome. Genome Res. 20, 1133-1142. doi: 10.1101/gr.106773.110

Doyon, Y., and Côté, J. (2016). Preparation and analysis of native chromatinmodifying complexes. Methods Enzymol. 573, 303-318. doi: 10.1016/bs.mie. 2016.01.017

Doyon, Y., Cayrou, C., Ullah, M., Landry, A. J., Côté, V., Selleck, W., et al. (2006). ING tumor suppressor proteins are critical regulators of chromatin acetylation required for genome expression and perpetuation. Mol. Cell 21, 51-64. doi: 10.1016/j.molcel.2005.12.007

Doyon, Y., Selleck, W., Lane, W. S., Tan, S., and Côté, J. (2004). Structural and functional conservation of the NuA4 histone acetyltransferase complex from yeast to humans. Mol. Cell. Biol. 24, 1884-1896. doi: 10.1128/mcb.24.5.18841896.2004

Dyer, P. N., Edayathumangalam, R. S., White, C. L., Bao, Y., Chakravarthy, S., Muthurajan, U. M., et al. (2003). Reconstitution of nucleosome core particles from recombinant histones and DNA. Methods Enzymol. 375, 23-44. doi: 10. 1016/S0076-6879(03)75002-2

Einhauer, A., and Jungbauer, A. (2001). The FLAGTM peptide, a versatile fusion tag for the purification of recombinant proteins. J. Biochem. Biophys. Methods 49, 455-465. doi: 10.1016/S0165-022X(01)00213-5

Engeholm, M., de Jager, M., Flaus, A., Brenk, R., van Noort, J., and OwenHughes, T. (2009). Nucleosomes can invade DNA territories occupied by their neighbors. Nat. Struct. Mol. Biol. 16, 151-158. doi: 10.1038/nsmb.1551

Farnung, L., Ochmann, M., and Cramer, P. (2020). Nucleosome-CHD4 chromatin remodeler structure maps human disease mutations. eLife 9:e56178. doi: 10. 7554/eLife.56178

Fazzio, T. G., Huff, J. T., and Panning, B. (2008). An RNAi screen of chromatin proteins identifies Tip60-p400 as a regulator of embryonic stem cell identity. Cell 134, 162-174. doi: 10.1016/j.cell.2008.05.031
Grant Number RGPIN-2016-05844, awarded to AF-T), and the Canadian Institutes of Health Research (CIHR Operating Grant Number FDN-143314, awarded to JC). JC is a tier 1 Canada Research Chair in Chromatin Biology and Molecular Epigenetics. AF-T is a tier 2 Canada Research Chair in Molecular Virology and Genomic Instability and is supported by the Foundation J.-Louis Lévesque.

Feng, Y., Vlassis, A., Roques, C., Lalonde, M., González-Aguilera, C., Lambert, J., et al. (2016). BRPF 3- HBO 1 regulates replication origin activation and histone H3K14 acetylation. EMBO J. 35, 176-192. doi: 10.15252/embj.201591293

Gibson, T. J., Seiler, M., and Veitia, R. A. (2013). The transience of transient overexpression. Nat. Methods 10, 715-721. doi: 10.1038/nmeth.2534

Gorrini, C., Squatrito, M., Luise, C., Syed, N., Perna, D., Wark, L., et al. (2007). Tip60 is a haplo-insufficient tumour suppressor required for an oncogene-induced DNA damage response. Nature 448, 1063-1067. doi: 10. 1038/nature06055

Haruki, H., Nishikawa, J., and Laemmli, U. K. (2008). The anchor-away technique: rapid, conditional establishment of yeast mutant phenotypes. Mol. Cell 31, 925-932. doi: 10.1016/j.molcel.2008.07.020

Havasi, A., Haegele, J. A., Gall, J. M., Blackmon, S., Ichimura, T., Bonegio, R. G., et al. (2013). Histone acetyl transferase (HAT) HBO1 and JADE1 in epithelial cell regeneration. Am. J. Pathol. 182, 152-162. doi: 10.1016/j.ajpath.2012.09.017

Hockemeyer, D., Soldner, F., Beard, C., Gao, Q., Mitalipova, M., Dekelver, R. C., et al. (2009). Efficient targeting of expressed and silent genes in human ESCs and iPSCs using zinc-finger nucleases. Nat. Biotechnol. 27, 851-857. doi: 10. 1038/nbt.1562

Hopp, T. P., Prickett, K. S., Price, V. L., Libby, R. T., March, C. J., Cerretti, D. P., et al. (1988). A short polypeptide marker sequence useful for recombinant protein identification and purification. Bio/Technology 6, 1204-1210. doi: 10. 1038/nbt1088-1204

Hu, Y., Fisher, J. B., Koprowski, S., McAllister, D., Kim, M. S., and Lough, J. (2009). Homozygous disruption of the Tip60 gene causes early embryonic lethality. Dev. Dyn. 238, 2912-2921. doi: 10.1002/dvdy.22110

Huang, J., and Tan, S. (2013). Piccolo NuA4-catalyzed acetylation of nucleosomal histones: critical roles of an Esal tudor/chromo barrel loop and an epll enhancer of polycomb A (EPcA) basic region. Mol. Cell. Biol. 33, 159-169. doi: $10.1128 / \mathrm{mcb} .01131-12$

Ikura, T., Ogryzko, V. V., Grigoriev, M., Groisman, R., Wang, J., Horikoshi, M., et al. (2000). Involvement of the TIP60 histone acetylase complex in DNA repair and apoptosis. Cell 102, 463-473. doi: 10.1016/S0092-8674(00)00051-9

Jacquet, K., Fradet-Turcotte, A., Avvakumov, N., Lambert, J. P., Roques, C., Pandita, R. K., et al. (2016). The TIP60 complex regulates bivalent chromatin recognition by 53BP1 through Direct H4K20me binding and H2AK15 acetylation. Mol. Cell 62, 409-421. doi: 10.1016/j.molcel.2016.03.031

Kato, D., Osakabe, A., Arimura, Y., Mizukami, Y., Horikoshi, N., Saikusa, K., et al. (2017). Crystal structure of the overlapping dinucleosome composed of hexasome and octasome. Science 356, 205-208. doi: 10.1126/science.aak9867

Lalonde, M. E., Cheng, X., and Côté, J. (2014). Histone target selection within chromatin: an exemplary case of teamwork. Genes Dev. 28, 1029-1041. doi: 10.1101/gad.236331.113

Liang, F. S., Ho, W. Q., and Crabtree, G. R. (2011). Engineering the ABA Plant stress pathway for regulation of induced proximity. Sci. Signal. 4:rs2. doi: 10. 1126/scisignal.2001449

Lombardo, A., Cesana, D., Genovese, P., di Stefano, B., Provasi, E., Colombo, D. F., et al. (2011). Site-specific integration and tailoring of cassette design for sustainable gene transfer. Nat. Methods 8, 861-869. doi: 10.1038/nmeth.1674

Lowary, P. T., and Widom, J. (1998). New DNA sequence rules for high affinity binding to histone octamer and sequence-directed nucleosome positioning. J. Mol. Biol. 276, 19-42. doi: 10.1006/jmbi.1997.1494

Ma, Y., Kanakousaki, K., and Buttitta, L. (2015). How the cell cycle impacts chromatin architecture and influences cell fate. Front. Genet. 6:19. doi: 10.3389/ fgene.2015.00019 
Machida, S., Takizawa, Y., Ishimaru, M., Sugita, Y., Sekine, S., Nakayama, J. I., et al. (2018). Structural basis of heterochromatin formation by human HP1. Mol. Cell 69, 385.e-397.e. doi: 10.1016/j.molcel.2017.12.011

McGinty, R. K., Kim, J., Chatterjee, C., Roeder, R. G., and Muir, T. W. (2008). Chemically ubiquitylated histone H2B stimulates hDot1L-mediated intranucleosomal methylation. Nature 453, 812-816. doi: 10.1038/nature06906

Miotto, B., and Struhl, K. (2010). HBO1 histone acetylase activity is essential for DNA replication licensing and inhibited by geminin. Mol. Cell 37, 57-66. doi: 10.1016/j.molcel.2009.12.012

Muthurajan, U., Mattiroli, F., Bergeron, S., Zhou, K., Gu, Y., Chakravarthy, S., et al. (2016). In vitro chromatin assembly: strategies and quality control. Methods Enzymol. 573, 3-41. doi: 10.1016/bs.mie.2016.01.002

Nabet, B., Roberts, J. M., Buckley, D. L., Paulk, J., Dastjerdi, S., Yang, A., et al. (2018). The dTAG system for immediate and target-specific protein degradation. Nat. Chem. Biol. 14, 431-441. doi: 10.1038/s41589-018-0021-8

Nishimura, K., Yamada, R., Hagihara, S., Iwasaki, R., Uchida, N., Kamura, T., et al. (2020). A super-sensitive auxin-inducible degron system with an engineered auxin-TIR1 pair. Nucleic Acids Res. 48:e108. doi: 10.1093/nar/gkaa748

Numata, A., Kwok, H. S., Zhou, Q. L., Li, J., Tirado-Magallanes, R., Angarica, V. E., et al. (2020). Lysine acetyltransferase Tip60 is required for hematopoietic stem cell maintenance. Blood 136, 1735-1747. doi: 10.1182/blood.2019001279

Patel, A. B., Moore, C. M., Greber, B. J., Luo, J., Zukin, S., Ranish, J., et al. (2019). Architecture of the chromatin remodeler RSC and insights into its nucleosome engagement. eLife 8:e54449. doi: 10.7554/eLife.54449

Poepsel, S., Kasinath, V., and Nogales, E. (2018). Cryo-EM structures of PRC2 simultaneously engaged with two functionally distinct nucleosomes. Nat. Struct. Mol. Biol. 25, 154-162. doi: 10.1038/s41594-018-0023-y

Puig, O., Caspary, F., Rigaut, G., Rutz, B., Bouveret, E., Bragado-Nilsson, E., et al. (2001). The tandem affinity purification (TAP) method: a general procedure of protein complex purification. Methods 24, 218-229. doi: 10.1006/meth.2001. 1183

Rigaut, G., Shevchenko, A., Rutz, B., Wilm, M., Mann, M., and Seraphin, B. (1999). A generic protein purification method for protein complex characterization and proteome exploration. Nat. Biotechnol. 17, 1030-1032. doi: 10.1038/13732

Sadelain, M., Papapetrou, E. P., and Bushman, F. D. (2012). Safe harbours for the integration of new DNA in the human genome. Nat. Rev. Cancer 12, 51-58. doi: $10.1038 / \operatorname{nrc} 3179$

Schnitzler, G. R. (2000). Isolation of histones and nucleosome cores from mammalian cells. Curr. Protocols Mol. Biol. Chapter 21:Unit21.5. doi: 10.1002/ 0471142727.mb2105s50

Sekulic, N., and Black, B. E. (2016). Preparation of recombinant centromeric nucleosomes and formation of complexes with nonhistone centromere proteins. Methods Enzymol. 573, 67-96. doi: 10.1016/bs.mie.2016.01.014

Shen, H., and Laird, P. W. (2013). Interplay between the cancer genome and epigenome. Cell 153, 38-55. doi: 10.1016/j.cell.2013.03.008

Simon, M. D. (2010). Installation of site-specific methylation into histones using methyl lysine analogs. Curr. Protocols Mol. Biol. Chapter 21, Unit 21.18.1-10. doi: 10.1002/0471142727.mb2118s90
Steunou, A. L., Rossetto, D., and Côté, J. (2014). "Regulating chromatin by histone acetylation," in Fundamentals of Chromatin, eds J. Workman and S. Abmayr (New York, NY: Springer), doi: 10.1007/978-1-4614-8624-4_4

Thåström, A., Lowary, P. T., Widlund, H. R., Cao, H., Kubista, M., and Widom, J. (1999). Sequence motifs and free energies of selected natural and nonnatural nucleosome positioning DNA sequences. J. Mol. Biol. 288, 213-229. doi: 10.1006/jmbi.1999.2686

Utley, R. T., Owen-Hughes, T. A., Juan, L. J., Côté, J., Adams, C. C., and Workman, J. L. (1996). In vitro analysis of transcription factor binding to nucleosomes and nucleosome disruption/displacement. Methods Enzymol. 274, 276-291. doi: 10.1016/S0076-6879(96)74024-7

Wagner, F. R., Dienemann, C., Wang, H., Stützer, A., Tegunov, D., Urlaub, H., et al. (2020). Structure of SWI/SNF chromatin remodeller RSC bound to a nucleosome. Nature 579, 448-451. doi: 10.1038/s41586-0202088-0

Wang, H., Farnung, L., Dienemann, C., and Cramer, P. (2020). Structure of H3K36-methylated nucleosome-PWWP complex reveals multivalent crossgyre binding. Nat. Struct. Mol. Biol. 27, 1-6. doi: 10.1038/s41594-0190345-4

Wojcik, F., Dann, G. P., Beh, L. Y., Debelouchina, G. T., Hofmann, R., and Muir, T. W. (2018). Functional crosstalk between histone H2B ubiquitylation and H2A modifications and variants. Nat. Commun. 9:1394. doi: 10.1038/s41467018-03895-5

Yesbolatova, A., Saito, Y., Kitamoto, N., Makino-Itou, H., Ajima, R., Nakano, R., et al. (2020). The auxin-inducible degron 2 technology provides sharp degradation control in yeast, mammalian cells, and mice. Nat. Commun. 11:5701. doi: 10.1038/s41467-020-19532-z

Zhang, Y., and Kutateladze, T. G. (2019). Methylation of histone H3K79 by dot1l requires multiple contacts with the ubiquitinated nucleosome. Mol. Cell 74, 862-863. doi: 10.1016/j.molcel.2019.05.013

Conflict of Interest: The authors declare that the research was conducted in the absence of any commercial or financial relationships that could be construed as a potential conflict of interest.

Publisher's Note: All claims expressed in this article are solely those of the authors and do not necessarily represent those of their affiliated organizations, or those of the publisher, the editors and the reviewers. Any product that may be evaluated in this article, or claim that may be made by its manufacturer, is not guaranteed or endorsed by the publisher.

Copyright (c) 2021 Galloy, Lachance, Cheng, Distéfano-Gagné, Côté and FradetTurcotte. This is an open-access article distributed under the terms of the Creative Commons Attribution License (CC BY). The use, distribution or reproduction in other forums is permitted, provided the original author(s) and the copyright owner(s) are credited and that the original publication in this journal is cited, in accordance with accepted academic practice. No use, distribution or reproduction is permitted which does not comply with these terms. 